\title{
THE USE OF MINICOMPUTERS IN A DISTRIBUTED INFORMATION PROCESSING SYSTEM-A FEASIBILITY STUDY
}

By Stanley M. Longwill, Jesse M. McNellis, and Douglas R. Posson

U.S. GEOLOGICAL SURVEY

Open-File Report 80-326

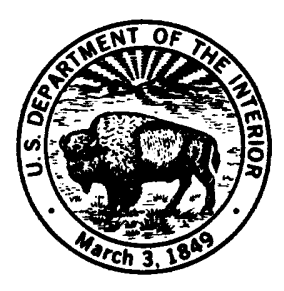




\title{
UNITED STATES DEPARTMENT OF THE INTERIOR
}

CECIL D. ANDRUS, Secretary

\section{GEOLOGICAL SURVEY}

\author{
$\mathrm{H}$. William Menard, Director
}

For additional information write to:

Chief Hydrologist

437 National Center

U.S. Geological Survey, WRD

Reston, Virginia 22092 
II Executive summary • • • • • • • • • • • • • 6

III Acquisition of prototype systems - •

IV Prototype minicomputer configuration - . - . . . . . 99

V Minicomputer installation and operations . . . . . . . . 13

A. Installation of minicomputer systems . . . . . . . 13

1. Logistics . . . . . . . . . . . . . 13

2. Environment . . . . . . . . . . . . 13

3. Other • . • • . . . . . . . . . 13

B. Operation . . . . . . . . . . . . . . 14

1. Attended . . . . . . . . . . . . . 14

2. Unattended . . . . . . . . . . . . . 14

C. Hardware malfunctions . . . . . . . . . . . . 15

1. CPU and memory . . . . . . . . . . . 15

2. Peripherals . . . . . . . . . . . 15

D. Hardware deficiencies . . . . . . . . . . . 16

1. CPU and memory . . . . . . . . . . . 16

2. Peripherals . . . . . . . . . . . 16

E. Software deficiencies . . . . . . . . . . . 17

1. System functions . . . . . . . . . . . 17

2. Processors . . . . . . . . . . . . 17

a. FORTRAN - . . . . . . . . . . . . 17

b. Editor . . . . . . . . . . . . . 18

c. HASP emulator . . . . . . . . . 18

d. 200UT emulator . . . . . . . . . 18

e. Tape utilities . . . . . . . . . 18

F. Telecommunications - . • . . . . . . . . . 18

G. Programming • • • • . • • . . . . . . . 19

H. Training • • - . . . . - . . . . . . . . 19

I. Maintenance • • • • • • • • • • • • • 20

VI Effects of minicomputer on Kansas and New Mexico Districts . $~ 21$

VII Cost/benefit analysis • • • • • • • • • • • • • • 25

VIII Proposed implementation plan of distributed information

processing throughout Water Resources Division . . . . . . 29

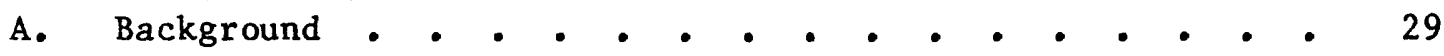

B. WRD computing requirements . . . . . . . . . . . 31 


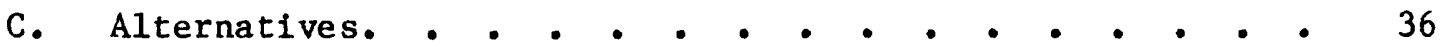

D. Effects on central computer operation . . . . . . . 40

E. Effects on national networks . . . . . . . . . . 41

1. Effect of minicomputers on WATSTORE - . . • . . 41

2. Effect of minicomputers on NWUDS . • . . . . . 41

3. Effect of minicomputers on NAWDEX . . . . . . 41

F. Recommendations. • • • • • • • • • • • • • 42

IX. Appendix • . . . . . . . . . . . . . . 43

Table 1 (Data processing cost comparison summary, Kansas) - 45

Table 2 (Data processing cost comparison summary, New Mexico). 46

Table 3 (Data processing cost comparison FY 79, KS) . • • 47

Table 4 (Data processing cost comparison FY 80, KS) . . . . 48

Table 5 (Data processing cost comparison FY 81, KS) • . . 49

Table 6 (Data processing cost comparison FY 82, KS) • . • 50

Table 7 (Data processing cost comparison FY 83, KS) • • • 51

Table 8 (Data processing cost comparison FY 84, KS) • • . 52

Table 9 (Data processing cost comparison FY 79, NM) . • • . 53

Table 10 (Data processing cost comparison FY 80, NM) • • • 54

Table 11 (Data processing cost comparison FY 81, NM) • • • 55

Table 12 (Data processing cost comparison FY 82, NM) • • • 56

Table 13 (Data processing cost comparison FY 83, NM) • • . 57

Table 14 (Data processing cost comparison FY 84, NM) • • • 58

Table 15 (Estimated yearly personnel cost savings resulting

from conversion to minicomputer in WRD, Kansas). . . 59

Table 16 (Estimated yearly personnel cost savings resulting

from conversion to minicomputer in WRD, New Mexico) . 64

\section{ILLUSTRATIONS}

Figure 1 (Minicomputer system, USGS WRD District office,

Lawrence, Kansas) • . • . • • • . • 10

Figure 2 (Minicomputer system, USGS WRD District Office,
Albuquerque, New Mexico) - • • • • • • • $~$

Figure 3 (Memorandum to the record from D. L. Hart) . . . 24 
This is a report of distributed information processing at two Water Resources Division (WRD) District Offices, Kansas and New Mexico, from January through November 1979. It also includes a cost/benefit analysis originally prepared by L. S. Gordon, Operations Research Analyst of the Program Analysis Office, Director's Office. This analysis was requested by Philip Cohen, at that time Assistant Chief Hydrologist for Scientific Publications and Data Management. The discussion in Section VII, Cost/Benefit Analysis, and the tables in Section IX, Appendix, are adaptations of the original concepts proposed by Mr. Gordon.

Other sections of this report discuss the effects distributed processing may have on existing WRD computer activities, and include recommendations for continued development of distributed information processing in the Division. 
II. Executive Summary

The Water Resources Division, Geological Survey, in planning for an upgraded data processing capability, recelved authorization from the Interior Department Office of ADP and Telecommunications Management to test the application of minicomputers to the Division's field programs. Subsequently, two minicomputers were procured and installed in the district offices in Lawrence, Kansas, and Albuquerque, New Mexico, so that a feasibility study of distributed data processing could be accomplished. This report presents these experiences and results obtained in a 9-month test period.

The minicomputers have been used to support the district data collection and analysis program, the hydrologic analysis program, and administrative applications. Typical applications are Ground-Water Site-Inventory pre-edit; water-quality, sediment, header file, and peak flow data entry, checking, update, and tracking; two- and three-dimensional ground water flow models; hydraulic analysis programs including backwater and culvert computations; and administrative applications including control property inventory, and authorization and allocation of funds data entry checking, updating, and tracking.

Minicomputer operation in both district offices has proven to be cost effective. The value of projected annual manpower savings plus reduction in costs of mainframe computer processing and remote job entry terminal (RJE) leasing is greater than the annual cost to lease and maintain the minicomputer hardware and software. Total savings in the Kansas district over a 5-year period (1980-1984) should approximate $\$ 349,000$ and in the New Mexico district, $\$ 316,000$. Both estimates have been discounted to present value at 10 percent.

Equally important are the increased work performance (efficiency) and improved morale that can result from the diversion of district manpower from tedious labor intensive data compilation and analysis to more creative and professional activities. The project activities associated with the Hydrologic Investigation Section and Hydrologic Data Section in each district appear to offer the greatest potential for transfer of routine data processing functions from professionals to technicians. Cost reduction has already occurred in two major areas--hydrologic modeling and data entry operations.

During the study, the following six options were considered in view of the current computing requirements of WRD.

1. Continuation of current system.

2. Improvement of current system.

3. Major modification of current system.

4. Installation of hierarchical distributed processing system.

5. Installation of modified hierarchical distributed processing system.

6. Establishment of integrated information system. 
of these options, only the last one can provide stand alone processing at WRD fleld offices. Stand alone processing permits the automation of many labor intensive processes such as word processing, data entry, text editing, application program development, debugging and execution, hydrologic-simulation modeling, and automatic updating of the national data bases.

Therefore, it is recommended that the Water Resources Division Implement an integrated information system and procure for district use minicomputers that have the following features:

1. Conventional data processing in batch, interactive, and remote job entry modes.

2. Word and text processing.

3. Report preparation capability, including interface to typesetting equipment.

4. Support of a Data Base Management System (DBMS) package.

5. The capability of communicating with any other WRD integrated information system to allow teleconferencing, electronic mail service, and the sharing of system and application programs.

6. The capability of being interfaced to data gathering devices both in the fleld and in the office. Such devices include laboratory instruments, portable point of entry, data logging, and data conversion equipment.

7. Each integrated information system must be capable of running all tasks described above concurrently.

8. Each system must be capable of being assembled from a large family of compatible processors and peripherals to meet the needs and budget restrictions of each WRD district and subdistrict operation. 
III. Acquisition of Prototype Systems

The WRD began a concerted effort In 1976 to evaluate the potential use of minicomputers at district level. A report, resulting from this effort by J. M. McNellis (June 1976), summarized the results of a minicomputer feasibility study that was prepared in the form of a preliminary request for acquisition of minicomputers for use in the WRD. The report also incorporated the results of D. R. Posson's effort in 1975 to obtain a minicomputer system for the New Mexico District. The feasibility study, which was circulated for comment, had strong input from the districts and formed the basis for the Request for Proposals (RFP) that resulted in the procurement of prototype minicomputers now located in New Mexico and Kansas.

A RFP team was selected, including members from each WRD region and headquarters, the Computer Center Division (CCD), and the Administrative Division. It was charged with designing specifications for a minicomputer system which would be capable of supporting a district's computational needs. Identical central processor units (CPU's) and operating system software were specified to encourage applications program compatibility.

The team designed a live test demonstration package which simulated expected job mixes in the two district offices. Large simulation models were run concurrently with heavy input/output programs, while many interactive terminals were executing FORTRAN compllations. At the same time, RJE was required to access USGS computers and other mainframes in use by districts.

Those vendors which successfully completed the live test demonstration within the allowable elapsed time perlods were requested to submit a best and final bid. Harris Corporation ${ }^{1}$ submitted the lowest bid and a contract was awarded to them.

Two Harris S125 minicomputer systems were dellvered and installed at the fleld sites. The first system was delivered to the WRD District office in Lawrence, Kansas, on November 22, 1978. Installation was completed by Harris Corporation personnel on December 30, 1978. This system is managed by Jesse M. McNellis, Hydrologist under the supervision of Joseph S. Rosenshein, District Chief. The second system was delivered to the Albuquerque, New Mexico District Office on January 16, 1979. Harris field service personnel readied this system for operation beginning February 26, 1979. The New Mexico system has been managed by Douglas R. Posson under the supervision of William E. Hale, former District Chief, and James F. Daniel, District Chief.

Acceptance testing of each system began immediately after installation. The standard of performance as defined in the contract was reached within several weeks and and both systems were formally accepted by the Government.

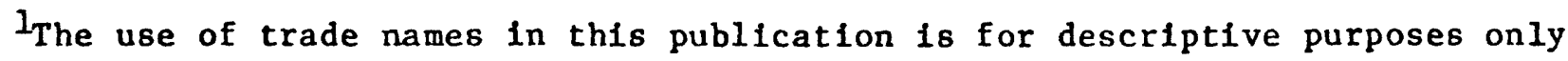
and does not constitute endorsement by the U.S. Geological Survey. 
IV. Prototype Minicomputer Configuration

The Harris S125 minfcomputer systems installed in Kansas and New Mexico WRD offices are of similar design configuration (See Figures 1 and 2). The S125 is a high performance, disk-based, virtual memory computer system for performing concurrent interactive terminal time-sharing, multi-batch, remote job entry and real-time processing. Each system includes a 24-bit word central processor (Harris model Slash 6) having a cycle time of 300 nanoseconds. Each processor is equiped with $624 \mathrm{~K}$ bytes of MOS error correcting memory, eight priority interrupts, scientific arithmetic unit, power fail shutdown and restart, ROM bootstrap, turn key panel and power supplies. Integral peripheral equipment consists of two 80 megabyte storage module disk drives with controller, one 9 track $800 / 1600$ bits per inch magnetic tape unit, one 600 line per minute printer, a 300 card per minute card reader and an operator's console (OPCOM) which is an interactive CRT. Each system is also linked to a variety of interactive terminals such as CRT devices and low speed impact printers.

The systems are driven by a software package known as the virtual memory manager (VULCAN). VULCAN is a priority structured, demand-paged, multiprogramming operating system. It supports multi-level batch processing, interactive terminal time sharing, multiple remote-job-entry, real-time operation, and several languages including FORTRAN, BASIC, COBOL, and the Harris macro assembler.

All interactive terminals now in use on the Lawrence, Kansas, system are direct-wired to the computer, with terminal cables to each office. The larger offices are equipped with more than one cable. Twelve of the terminals are the CRT type which display a maximum of 24 1ines of 80 characters per line and are set up to operate at a speed of approximately 960 characters per second. Two impact printers (AJ832) and a portable terminal (TI765) are also direct wired to the system. These are slow speed devices operating at approximately 30 characters per second. All terminals are distributed throughout the district office with each project and section having access to a terminal.

RJE traffic in Kansas is handled through a single dial-up synchronous port operating at 4800 bits per second. By using the Harris HASP/2780 emulator package, communication can be estab1ished with the IBM 370 computers at the USGS in Reston and the Itel AS5 equipment at the Department of Interior Computer Center in Washington, D.C. In addition, the Kansas District Office plans to establish communication linkages in the near future which will enable terminals in the subdistrict offices in Garden City and Salina to access the Harris S125 system in Lawrence.

At the New Mexico District office, thirteen CRT terminals and one slow speed impact printer (AJ832) are direct wired to the minicomputer. Distribution of terminals and terminal cables is similar to that in Kansas. Through the use of full duplex leased telephone lines, and data multiplexers (Figure 2), data communication can be established between the minicomputer and the State 
Ltgure - 1

Minlcomputer Syotew

USGS WRD Dietrict Offlce, Lawrence, Kansas

Basic Data Section Hydrologic Investigation Section Reports Section

Infoton CRT, 9600 bps

Infoton CRT, 9600 bps

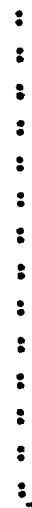

:Alr Conditioning:

: Unit

:$$
8
$$$$
8
$$

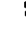

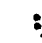

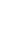

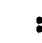$$
\text { - Mag Tape : }
$$$$
\text { : Drive : }
$$$$
\text { : }
$$

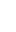

8

$:$

:

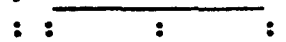

: $5530: 5531:$

: 80mb : 80mb :

: : Disk : Disk

$:$

$:$
Infoton CRT, 9600 bps

Infoton CRT, 9600 bps

Infoton CRT, 9600 bps

foton CRT, 9600 bps

832 KSR Teleprinter,

00 bps

TI765 KSR Teleprinter,

300 bps
Infoton CRT, 9600 bps

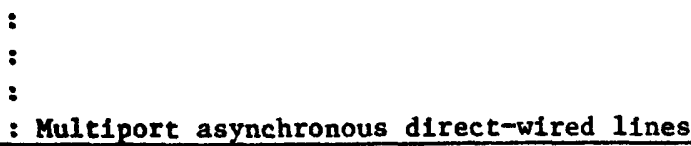

Adminietration Section

Infoton CRT, 9600 bps

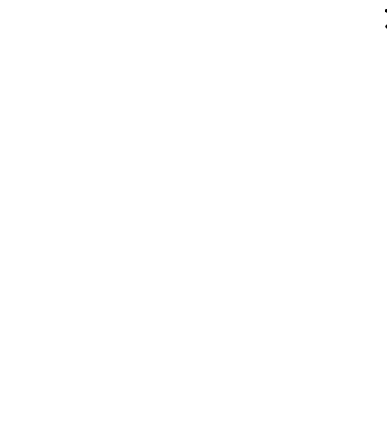

Computer Section

Infoton CRT, 9600 bps Infoton CRT, 9600 bps Beehtve CRT, 9600 bps

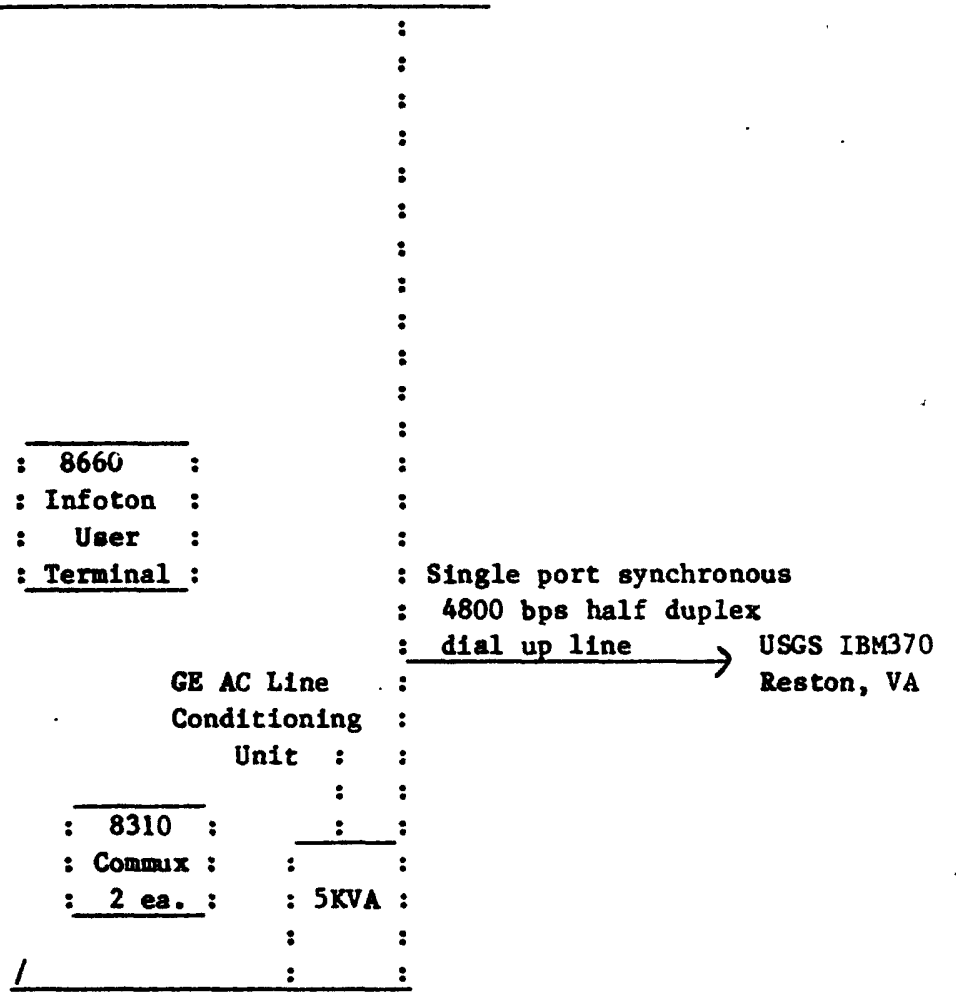


Basic Data Section Hydrologic Investigation Section

Datagraphix 132B CRT

Infoton CRT, 9600 bps

:

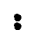

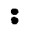

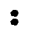

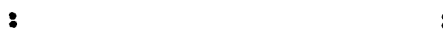

Infoton CR

Infoton CRT, 9600 bps

Infoton CRT, 9600 bps

Infoton CRT, 9600 bps
Infoton CRT, 9600 bps

Multiport asynchronous direct-wired.1ines
Reports Secrion

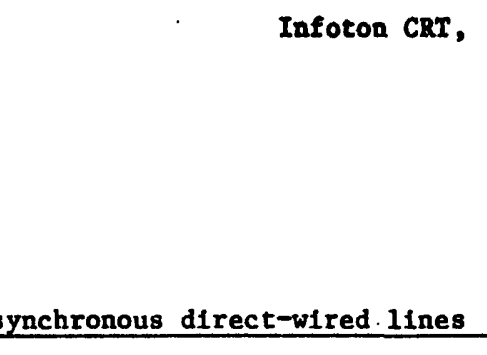

Topaz AC line :

conditioning : 15KVA

units - - :

: $5530: 5531:$

: $80 \mathrm{mb}: 80 \mathrm{mb}$ :

: Disk : Disk :

: : : :

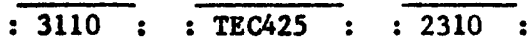

: Card : : User : : OpCom :

: Reader: : Terminal:

\begin{tabular}{lll}
\hline$:$ & \\
$:$ & 4120
\end{tabular}

\section{Computer Section}

Infoton CRT, Infoton CRT, 9600 bps Dec VT-100, CRT, 9600 bps AJ832 KSR Teleprinter, 300 bps TEC425 CRT, 9600 bps TEC425 CRT, 9600 bps
25KVA : Single port asynchronous multiplexed to : single synchronous 2400 bps full duplex : leased line $\rightarrow$ Subdistrict office Albuquerque, NM Infotron CRT, 2400 bps

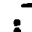

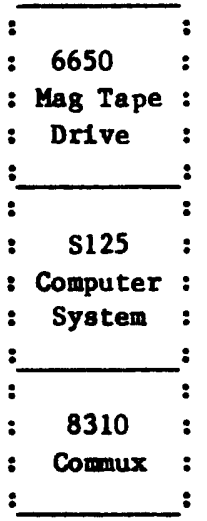
8310 : Single port asynchronous multiplexed to Commux : single synchronous 2400 bps full duplex : leased line $\rightarrow$ Subdistrict Office $\longrightarrow$ Santa Fe, NM Infoton CRT, 2400 bps$$
\text { : }
$$

- Dual port asynchronous multiplexed to : single synchronous 2400 bps full duplex : leased line State Engineer Jffice Santa Fe, MM TEC425 CRT, 2400 bp8 AJ832 KSR Teleprinter. 300 bps

: Single port synchronous

4800 bps half duplex dial up

$\begin{array}{ll}: \longrightarrow \text { IIne } & \begin{array}{l}\text { USGS IBM370 Reston } \\ \text { Kirtland AFB CDC } \\ \text { Albuquerque, NM }\end{array}\end{array}$


Engineer's Office in Santa Fe and between the minicomputer and subdistrict offices in Albuquerque, Santa Fe, and Carlsbad. One CRT terminal is located at each of these offices as well as an impact printer (AJ832) in all but the Carlsbad office.

As in Kansas, a single dial-up synchronous port along with the HASP emulator package provides connection to the USGS computers in Reston. Using the same synchronous port and the Harris supplied 200UT emulation software, the Albuquerque minicomputer can be linked with Control Data Corporation computers at nearby Kirtland Air Force Base. 
V. Minicomputer Installation and Operation

\author{
A. Installation of minicomputer systems \\ 1. Logistics
}

Numerous physical modifications to the computer rooms were made. The scheduling of these modifications caused delays and frustrations.

\title{
2. Environment
}

Correct electric service must be installed. Requests for this service must be processed through GSA. Lead times for the New Mexico system were 120 days from order to installation.

Considerations must be given to stable electrical power, at 110 and 220 volts, with inline transformers to dampen aberrant spikes in the incoming power. The Kansas system uses one isolation transformer. The New Mexico system uses two isolation transformers and two voltage regulators.

An alternative is to use portable line-conditioning units, which are not permanent alterations to a GSA site. Lead times and costs may be significantly reduced.

Alr conditioning is necessary at both sites. The Kansas system uses two window units with a total of 2 tons $(24,000$ BTU) capacity. The New Mexico system requires GSA approval because of leasing arrangements. Lead times exceed 300 days.

Humidity control may be required in extremely humid or arid geographic areas. The New Mexico system consumes approximately 25 gallons per day to raise the humidity above static-electricity causing levels. The Kansas system may use dehumidifiers during humid summer months. Ideally, the air conditioning systems should monitor and control humidity properly.

Wiring of offices for terminal use may require GSA approval and competitive bids. Special shielded cable (Belden 8723) costing less than 10 cents per foot was used. Ten thousand feet of cable were used in Kansas and twelve thousand feet in New Mexico. Hard-wired terminal connections require custom soldering or crimping of the RS-232 connectors to the Belden 8723 shielded cable. This skill is quickly mastered by technicians.

\section{Other}

A library of magnetic tapes is required for system and user backup and for transfer of files from the Harris system to other systems. The New Mexico system has 250 tapes and Kansas 200 tapes in their libraries. 
Fire extinguishers loaded with Halon 1211 are necessary in the computer room and at terminal locations.

Adequate storage space for paper, tapes, ribbons, and other supplies must be available.

\section{B. Operation}

The contract for the minicomputers requires that the systems maintain a minimum uptime of 90 percent of a normal work day. The level of uptime on the systems meets that requirement. Actual uptime on the Kansas system is about 97 percent.

\section{Attended Operation}

In Kansas, the minicomputer is running 24 hours per day. When the first users arrive around 0700 hours, the computer is checked to insure all is well. About 0730 , a technician from the Basic Data Section initiates HASP on the system and telephones the IBM computers in Reston to retrieve overnight jobs. The technician returns to the Basic Data Section and occasionally monitors HASP activity. When there is no further activity between Harris and the IBM computer, the link is terminated.

The minicomputer operator works from 0900 to 1730 on Mondays and to 1630 on Tuesday through Friday. When she arrives, she checks the system status, separates output on the printer, and performs routine tasks. She cleans the printer and the tape drive, replaces printer ribbons and paper when necessary, handles system accounting and initiates HASP when jobs are in the HASP spool. Just before going to lunch, she initiates backup procedures to keep on tape the information accummulated in the computer since the previous day or week. Once a month she does a monthly backup. In addition, she monitors and updates the tape library, monitors system uptime, catalogs system message files, and works with users on problems they may have.

Daily and weekly backups are copied to a tape 1200 feet long, at a density of 1600 bits per inch (BPI), and are run as a batch job over lunch, taking from 15 to 30 minutes to complete. Monthly backups require three tapes, 2400 feet long, at 1600 BPI, and are run as batch jobs on Wednesday afternoon, taking from 1 to 2 hours. Daily backup tapes are reused every 8 days, weekly tapes are reused every 5 weeks, and monthly tapes may be reused every 13 months.

\section{Unattended Operation}

The Kansas system has been running 24 hours per day, 7 days per week since May 1979. It is unattended each day from closing time until morning and is unattended on the weekends. 
The computer in New Mexico is powered off after daily

operations are complete. Twenty-four hour operations will commence as soon as air-conditioning is installed.

\section{Hardware Malfunctions}

are minor.

Harris hardware is performing quite well. The problems noted

\section{CPU and Memory}

Problems were encountered with the MOS memory boards and the Scientific Arithmetic Unit (SAU) during the first 3 months after installation. The errors could not always be attributable to memory. System errors which were actually memory failures (generally read/write errors) would appear as software errors (e.g., FORTRAN or Sort/Merge would malfunction) or as other types of hardware error (messages through the multiplexer to/from terminals would be erroneous). Electronic failures are to be expected in the early months of operation. The services of a field service representative from Harris were required to trace and correct these errors.

\section{Periphera1s}

A 5-volt power supply on one multiplexer self-destructed and was replaced by the Harris field service representative.

Mechanical components sometimes fail early but generally tend to fail after extended use. Mechanical failures have included a bushing on a card reader, a motor on a printer, and a plastic sprocket on a printer.

The line printer destroyed $\$ 20$ ribbons regularly due to skewing of the ribbon to one side of the drum or the other. A ribbon-centering device costing $\$ 475$ was purchased, and installed, and corrected the problem.

Failure of terminal devices has occurred. Capacitors and transistors in the CRT terminals have been responsible. While this is aggravating when a failure occurs in the District office, it becomes a more serious problem when it occurs at a field office 300 miles away. Any contract should clearly specify the obligations of the vendor's field service office in this regard.

The synchronous communications board, required for $\mathrm{RJE}$, appears to be heat-sensitive. If the computer room ambient temperature exceeds 94 degrees Fahrenheit, RJE may not run reliably. Harris recommends ambient temperatures of no greater than 80 degrees for normal operation. All other system components, however, did run reliably above 94 degrees. 
The New Mexico disk controller has malfunctioned due to the failure of individual chips. This was caused by overheating within the disk cabinet when the cabinet doors were closed. This should not be a problem after air conditioning is installed. It has not been a problem with the Kansas system.

D. Hardware deficiencies

1. CPU and memory

It is desirable to have a capacity for more physical memory (current limit 624 kilobytes) to support more interactive terminals simultaneously without degradation of response times.

\section{Peripherals}

Terminal devices with 80 characters/line are not satisfactory. Terminals with 132 characters/line, upper and lower case letters, and with programmable stand-alone editing and processing capabilities are preferred.

All terminal devices should have a keyboard touch capable of pleasing the most demanding typists. Printing terminals capable of printing at speeds greater than 30 characters per second and line printers running at 200 to 300 lines per minute are desirable at remote locations.

Line printer drum does not have the underscore (_) character. Some WATSTORE software applications require the underscore. A new drum has been ordered with this capability.

Disks have been very reliable. However, disks with capacity larger than $80 \mathrm{mb}$ may be necessary for larger systems. This limit has not yet caused problems for users, but large data bases will require more disk capacity.

It may be necessary to interface peripherals such as plotters, digitizers, Mitron paper tape readers, and field sample monitors to the minicomputer. The manufacturer of the peripheral should be responsible for the interface.

Communications multiplexer baud rates and half/full duplex settings should be re-settable without requiring wire-wrapping of the board itself.

Terminal communications should be run without CPU interrupts. Large volume interactive communications have the potential to burden the CPU unnecessarily with character handling. DMA (direct memory access) communications should be installed on future systems. 


\section{E. Software deficiencles}

The Harris software, both fob control and processors, is quite good, well documented, and easy to use.

Many job control functions are easily accomplished with job control programming. These functions, called macros, are executed with the entry of just one command at a terminal (or from a batch job) and are comparable to cataloged procedures on the IBM System 370 Computer in Reston.

\section{System functions}

Virtual memory addressing space should be larger than $256 \mathrm{kw}$. More addressing space would allow larger simulation models to be run.

OPCOM commands should be available to allow the operator to monitor the virtual memory, real memory, CPU use, and I/O activity on a jobby-job basis. This information is provided for the complete system, but not for individual jobs.

OPCOM commands should be available to clear an I/O channel which is inoperative. Without this support, a re-boot of the system is required.

The operator should be able to alter the baud rates and other characteristics of individual ports on the communications multiplexer from the OPCON. It is currently necessary to regenerate the system to do this.

The terminal control software (TTY handler) should be more versatile. Specifically, it should allow for type-ahead and for escape code sequences. The first allows a terminal user to continue keying information while a previously entered command is executing. The second supports the intelligence of many commercially available terminal devices. These often use a sequence of commands which begins with the escape key. With the Harris TTY handler, an escape aborts the command.

\section{Processors}

\section{a. FORTRAN}

Executable code is limited to $64 \mathrm{k}$ words. Data

arrays may be $256 \mathrm{kw}(768 \mathrm{~kb})$.

Text data (enclosed in quotes) are not allowable as output 1ist. For example, WRITE(LFN,FMT) 'PRINT THIS TEXT' is not allowed. 


\section{b. Editor}

The Harris text editor is very powerful, in that Editor commands may be interspersed with other Job Control commands, and it has a full suite of line and character editing commands. However, it is a file processor, rather than a buffer processor. As such, it takes unnecessarily long to perform some rather simple updates on large files. Fortunately, an excellent version of the QED editor has been installed. It was written by Bell Labs and modified to run on a Harris at the University of Illinois. QED gives the TTY user a powerful, buffer-processing, text editing capability.

\section{c. HASP emulator}

HASP would intermittently not transmit blocks of data from the Harris to the host, and HASP would send jobs destined for a user disk area to the line printer when not desired. These problems are resolved with the $07 A$ version of VULCAN.

HASP would get out of synchronization with operator messages. Messages entered from OPCOM and from user terminals would not be transmitted until subsequent messages were entered. This problem was resolved with the 07B version of VULCAN. HASP works correctly and reliably at the New Mexico and Kansas sites now.

\section{d. 200UT emulator}

The three problems identified above for HASP also occured with 200UT, and have been corrected by Harris. Other problems that occur intermittently still exist, and are being worked on by Harris.

\section{e. Tape utilities}

Harris job control cannot copy to or read from a blocked magnetic tape file directly. A program and macro have been written to do this.

The Harris tape driver software causes the drive to stop when blank tape is read. This is common throughout the industry, but undesirable. On some occasions, it is necessary to re-boot the system when this occurs.

\section{F. Telecommunications}

The principal problem with telecommunications is that lead times required for approval of requests for lines through CCD and GSA are more than 6 months. As a result, final decisions about configuration and equipment must be made long before a system is installed. The ability to react to changing requirements or newer technology is severely diminished. 
There is some concern about compatibility between modems of two manufacturers. Specifically, the potential exists for subtle incompatibilities between modems. The experience so far indicates that this may not be a serious problem. The Vadic modems, purchased because of their extremely low cost, have proven to be compatible with 201B-equivalent modems from Be11 and Universal Data Systems.

\section{G. Programming}

It is clear that computer professionals provide quality program design, execution efficiency, and documentation. They are more likely to understand computer characteristics, and use them to good advantage. Indexed-sequential file structure, job-control programming, structured prograuming methods, and efficient memory accessing techniques are well known to the districts' more experienced computer users and relatively unknown to the less experienced users. However, all the users of the system are encouraged to program their own applications. The results are almost immediate and invariably solve an immediate problem. Methods are being devised and enacted which will insure that the most useful of the applications developed by users are well documented and can be distributed to potential users.

The Kansas District has designed and programmed an interactive application to document the programs developed within the district. This application builds a library of program names, descriptions of program use and I/O requirements, file requirements, etc. The file may be accessed and sorted by any user, and will display all necessary detail to any inquiring user. In addition, this system recommends a standardized file-naming convention for users. Thus, all users may gain familiarity with the applications developed by others.

\section{H. Training}

Training in the districts has taken three forms. The first, intensive instruction by contractor personnel; second, group instruction by district personnel; and last, individual instruction by district personnel. All training has been onsite.

The Harris training course in Vulcan familiarization required

2 weeks. The training was very intensive. It introduced terminology and concepts which were often totally foreign to the users. The idea of the course, i.e. total immersion, is good for some individuals. But, for many, it was too much, too quickly. Further, all trainees should have access to terminals not only during the course (which they did), but also immediately after the course (which many did not). The loss of knowledge about new concepts is very fast if the user cannot practice. 
The district group training courses were very well accepted. The format was similar to the Harris sessions. Two students shared each terminal. However, each course was 2 days long rather than 2 weeks. The students could comprehend 2 day's worth of new concepts and terminology. Further, each course was tailored to the expected uses of the students. Finally, the instructors were available after course completion for consultation with the individual students about their special needs.

Individual training has been provided formally and informally by Computer Section personnel. The typical case is one in which a user has a special requirement (specific application, specific repetitive terminal use, etc.). During the one-to-one sessions, each step of a process can be discussed and tested. Two key factors are at work in this situation. First, the psychology of this personalized help aids user acceptance of the system. Second, the Computer Section personnel are in a position to identify procedures which may be written to assist in a particular application. The frustrations which beginning users (often clerical and technical people) experience with a system can be decreased.

District group training is being planned for specific system utilities and applications. The programs scheduled for training at this time are FLECS (Structured Fortran), QED (Interactive text editor), SPSS (Statistical Package for the Social Sciences) and RJE (Harris Remote Job Entry). This type of training provides powerful tools for the user, tools which make the system better utilized.

\section{Maintenance}

The RFP required that maintenance be provided by the successful bidder. System maintenance is required on software and hardware, and covers problems with RJE, memory board failure, new issues of updated operating systems, and interfacing peripherals to the CPU. Maintenance is required on all components of the system. The contractor is required to respond to a request for maintenance within 4 hours of the request. Response consists of arriving at the computer site. The principal period of maintenance is defined as Monday through Friday from 0700 to 1800 .

These requirements have worked out well. Faster response would cost more. Four-hour response assures that service is locally based, and precludes a contractor from flying a maintenance man to the computer site from some distant location. The requirement for local service does not mean that the contractor must maintain a local warehouse full of spare parts. Harris utilizes air freight to transport replacement parts from their regional or central warehouses to the computer sites. Overnight delivery of parts can be expected. Minor repairs, including replacement of most commonly used chips, are typically done onsite. Included in the maintenance requirements are the specification that preventive maintenance (PM) be performed by the contractor on a regular and periodic basis. PM normally includes such tasks as changing filters on the disk drives, running diagnostics on various system components, and fine-tuning various system components and peripherals. 
VI.

Effects of Minicomputer on Kansas and New Mexico Districts

The effects of distributed processing in Kansas and New Mexico are many and varied particularly since all levels of personnel are involved in using the minicomputers. Use of distributed processing has transferred computing activities to the locations where data originate and are used. By doing this, cectain important efficlencies have resulted that have benefitted operations in both districts.

These include increased user control, utilization, and participation, increased responsiveress, faster turnaround, quicker access to the local data bases, more accurate data capture, and faster error correction. other economic benefits include lower costs for manpower and communication, and the ability to relate data processing costs to function.

Interactive processing promotes high expectations with regard to computer utilization and provides more self-satisfaction than other forms of computing. To those who are now using the minicomputer, it is clear that much of the energy previously expended in using the card-oriented RJE batch system was requiced simply to handle the logistics of the system itself rather than to implement the logic to solve the problem at hand. Because the system is responsive and easy to use, users who did not program before are now taking time to learn enough of a computer language to develop programs to assist in the completion of their projects.

A wide spectra of applications have been and are being developed and executed on the minicomputers by professional, technical, and clerical personnel in the two districts. Examples of programs and techniques that were identified by the districts prior to acquiring the minicomputers and that have been implemented on the Harris systems include:

1. A suite of water-quality programs

2. The backwater program known as E431

3. The culvert program known as $\mathbf{A} 526$

4. Two and three dimensional ground-water flow models

5. Ground-Water Site-Inventory pre-edit

6. Water-quality data entry checking, updating, and tracking

7. Sediment data entry checking, updating, and tracking

8. Control property inventory data entry checking, updating, and tracking

9. Authorization and allocation of funds data entry checking, updating, and tracking

10. Header File data entry update, checking, and tracking

11. Peak flow data entry checking, update, and tracking 
Items $5,6,7,10$, and 11 are appllcations whose end product is a file on the Harris machine that includes the correct JCL and is entered through RJE to WATSTORE in Reston. The Basic Data section utilizes these applications many times a week and staff from that section have been instrumental in the development of the software.

Development of some of the programs led to discussions of other uses for the data and these discussions have led to the development of new applications. This catalytic effect is very noticable in the two districts.

Distributed processing works well because it is available to the users. It has made many tasks easier, faster, and less error prone. For example, the text editing program, QED, has enabled users to produce report drafts and correspondence routinely on the minicomputer. The effect on the district typing staff is yet to be determined, but the effect on the authors themselves is liberating. They can work at their own pace, independent to some extent of the priorities and vacation schedules of the secretarial staff.

The advantages of interactive processing have become apparent to most employees in the two districts and they have readily accepted it as a beneficial tool. A measure of the acceptance of the Harris minicomputer is the number of hours that the interactive terminals are used each month. For example, terminal usage in the Kansas district has climbed by 15 percent per month during July, August, and September 1979. About 200 hours of terminal usage were logged during the last week of September. In the New Mexico district, terminals have been logged onto the computer more than 1,000 hours per month during the period July through November 1979 .

These statistics indicate that more employees are utilizing the computer and that costs per unit of use are therefore dropping.

Precise costs of programming are difficult to summarize in a distributed environment. While some programming is performed by the District Computer Sections, many applications are quickly improvised by project personnel themselves. It is not unusual for these programs to become widely used in a very short time, since they are developed to solve immediate needs. This class of program typically is used for data entry or error-checking, or may re-format digital model input into some report-presentable format. The costs of this type of program development are open to argument. Some insist that the costs are hydrologic project costs, since the data entry, error-checking and report output would have been done somehow during the course of the project effort.

Software development is quicker and cheaper when done interactively. This conclusion is based upon experience with software development on the Kansas and New Mexico minicomputers. Reliability of the system is also a major factor. The likelihood of a mainframe or a telecommunications network failure is higher than the probability of a district minicomputer breakdown. Another 
factor is cost itself. Charges for remote computing are priced by the job or session. Monthly lease and maintenance costs of the minicomputers are fixed by the terms of the contract; development costs on the minicomputer are a function of system usage.

Programming and debugging costs are extremely varlable when working with a remote system. Any systems and accounting algorithms changes made at remote computer centers can nullify estimates of project completion dates and costs. This is not a factor when using an inhouse minicomputer. Computer charges are based on total project funding and are levied accordingly.

Cost is a primary concern of project managers when considering digital modellng. Modeling costs can vary greatly according to the quality of the data available and the expertise of the modelers. In any event, complex logistics are involved in the coding, keypunching, and processing of the model input. Initial studies conducted on the minicomputers show that for most modeling situations it may be less expensive to enter the data and execute the model program interactively at the minicomputer than use a remote computer and process the model job in batch mode.

Early feedback from individual users suggests that the manpowerrelated cost savings can be very large and can exceed the estimates used in the cost/benefit analysis. For example, the High Plains Regional Aquifer System Analysis includes portions of northeastern New Mexico. The conversion of waterlevel data from the locally maintained Omniana data base, and from paper files to GWSI formats was expected to take approximately 6,000 manhours. Using format-conversion and error-checking programs developed by district project personnel, on the Harris minicomputer, the converison took $40 Q$ hours. The net savings exceeded $\$ 20,000$. (See Figure 3.)

Another example, also not included in Table 15, occurred in Kansas in November 1979. One phase of a project there includes determinations of inflows and releases from reservoirs. Based on 2 days of computations with a hand held calculator, the project chief estimated an additional 10 days would be required to complete the necessary computations. He decided to write a FORTRAN program to do the computations. He wrote, debugged, and executed the program and completed that phase of the project in a single day, thereby saving 9 days or more than $\$ 800.00$. As users gain experience, such examples will become commonplace rather than exceptions. 
Figure 3

Gate: Sept. 17, 1979

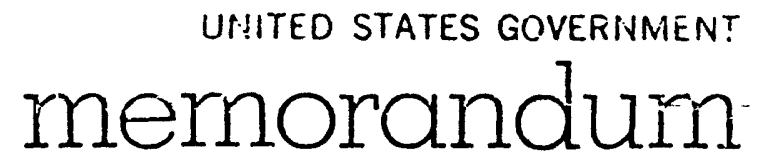

HEPYTOO OOF: D. L. Hart

SL:sect: Minicomputer

ro: The Record

Utilization of the minicomputer to convert approximately 5,800 well records in eastern New Mexico from the local OMNIANA system to the GWSI format was accomplished in approximatley 10 man weeks.

A program for the minicomputer was developed to convert Township-RangeSection and location within the section to a latitude-longitude location. The Lat-Long locations were merged with the OMNIANA data on a temporary disc file. Several programs were used to transfer the Lat-Long and OMNIANA data to a 2nd disc area in a format acceptable to the GWSI system. The file was then processed through an edit check furnished by the Kansas District. The edited file was then interfaced with the Reston system for additional Edit check programs. After the needed corrections were completed, the 5,800 sites $(60,600$ card images) were transferred to magnetic tape for transfer to trie Reston system. The job took an estimated 400 man hours.

Similar data conversion jobs done manually in the district indicate it takes ajout 1 hour to obtain a Latitude-Longitude location, code the data to GWSI format and run the edit checks. This equates to an estimated 5,800 man hours to convert the eastern New Mexico data manualiy.

The technical proficiency of the individuals working with the mini system must necessarily be higher than individuals using manual conversion methods. The approximate saving for the High Plains RASA (eastern New Mexico area) GWSI coding conversion is shown below.

CONVERSION OF OMNIANA to GWSI

$\begin{array}{ll}\text { Using minicomputer } & \\ 400 \text { man hours at } \$ 8.42 / \mathrm{hr} & \$ 3,368 \\ \text { Using manual methods } & \\ 6,000 \text { man hours at } \$ 4.02 / \mathrm{hr} & =23,374 \\ \text { Cost savings (salaries) } & \$ 20,006\end{array}$


Minicomputer operation in both test district offices has proven to be very cost effective. An economic study by Mr. L. S. Gordon, Operations Research Analyst of the Program Analysis Office, Director's Office, shows that annual cost savings, plus reduction in mainframe computer processing and data terminal leasing costs, are far greater than the lease and maintenance costs of minicomputer hardware and software. Tables 1 through 14 in the appendix of this report were prepared by $\mathrm{Mr}$. Gordon. Tables 15 and 16 itemize estimated cost savings resulting from district personnel using the Harris minicomputer to accomplish their jobs.

Over the 5-year period, 1980-1984, total savings in the Kansas district should approximate $\$ 349,000$ and in the New Mexico district should approximate $\$ 316,000$ (both estimates have been discounted to present value at 10 percent). See Summary Tables 1 and 2 . These estimated savings are conservative as they do not reflect adjustments for technical overhead charges and salary benefit payments.

By far the greatest potential savings will result from the diversion of district personnel from tedious labor intensive data compilation and analysis to more creative and professional activities.

Estimated personnel cost savings in the Kansas and New Mexico districts are $\$ 65,784$ and $\$ 86,007$ per year, respectively (see Tables 15 and 16). Savings were computed by multiplying step 5 salary rates from the general schedule salary table in effect on September 30, 1979, with man-months saved as estimated by project and section chiefs in the two districts.

Project activities associated with the Hydrologic Investigations Section in each district have the largest potential savings. Savings in this section are estimated at $\$ 25,000$ per year in Kansas and $\$ 38,000$ per year in New Mexico. Cost reduction occurs primarily in two major areas, hydrological modeling and data entry operations. Data for models can be input directly at the minicomputer terminals, edited and preprocessed in a search for errors. After model input has been debugged, the actual model simulation can be run on the minicomputer using either a two-dimensional or three-dimensional analysis program. Since the modeler can run the program interactively at his terminal, much time is saved in calibrating and archiving test runs. The output hydrographs and contour maps can be quickly reviewed by the user on the terminal screen and then printed, if necessary, on the system line printer or user impact printer. Verification, editing, and storage of the data are now much less time consuming. Statistical analysis, water budgets, channel geometry calculations, frequency analysis of peak flows and flood studies, for example, can be carried out interactively at user terminals. 
Basic Data Section personnel recognize that nearly as great a savings $(\$ 17,000$ per year for Kansas and $\$ 32,000$ per year for New Mexico) is possible in their activities. Annual report preparation, automated updates of rating curves and tables, and calculation assistance, including slope areas, drainage area plotting, and streambed cross-section plots are some of the surface water data activities which have been automated with the minicomputer systems. The systems have helped to improve response to public data requests, reduced travel costs to review and interpret basic records, and reduced the need to use WRD personnel to satisfy cooperator requests for data.

A variety of opportunities for savings exist in the District Administrative, Reports, and Computer Sections. Kansas district personnel estimate annual savings of $\$ 24,000$ in these area. Corresponding annual savings in the New Mexico district will probably total $\$ 15,000$. Administrative Section activities, which are being placed on-line at the local minicomputer, include inventory of controlled property, supply inventory and supply ordering, fiscal summaries and estimates of authorizations, project status, trave1, time and attendance data entry, and the district budget. The Report Section can archive annual report page header information so that updates and printing of the headers can be accomplished on-1ine. Plans are underway to archive entire reports and bibliographic information to be retrieved quickly when needed. In the computer section, program development and conversion can proceed more rapidly from interactive terminals since response time is appreciably shortened. The time required to back up files and and to restore purged files has been reduced. In the New Mexico District, the OMNIANA file management and programming system, which is difficult to use and maintain, will be phased out.

Since startup times of minicomputer operation did not coincide in the two districts, the cost comparison data for fiscal year 1979 (Tables 3 and 9) are shown for information. Cost comparison Tables 4 through 8 and Tables 10 through 14 show expenses, savings, and net amounts for the Kansas and New Mexico Districts, respectively, in fiscal years 1980 through 1984. The tables include, after the first year of operation (FY 1979), the following assumed percentage increases: 7 percent annual increase in personnel costs, 8 percent annual increase for lease and maintenance of Data 100 remote batch terminals, and 10 percent annual increase in charges for computer processing at the USGS in Reston, Virginia, and at the Department of the Interior in Washington, D.C.

According to the terms of the contract between the USGS and Harris Corporation, title to the minicomputer equipment will pass to the USGS on the 5-year anniversary date of each system. Certain items originally scheduled for delivery at the beginning of fiscal year 1980 (month 13) and fiscal year 1982 (month 37) were ordered as part of the initial configuration in September 1978. According to the terms of the contract, month 13 items will be fully paid for at the end of 48 months and month 37 items at the end of 24 months. 
This contractural arrangement was taken into account in calculating the annual lease and maintenance charges shown in Tables 3 through 14. It is for this reason that lease and maintenance charges reflect large price reductions in fiscal years 1981 and 1983.

Replacement of the remote job entry terminal by the minicomputer equipment has resulted in the elimination or reduction of several direct costs. The Data $100 / 78$ terminal in the Kansas District is to be transferred to the Virginia District in October 1979, thereby eliminating annual lease and maintenance costs of about $\$ 28,000$. Because of the ability to preprocess on the minicomputer much of the data formerly transferred to and processed on the mainframe computers at the University of Kansas, USGS Reston, Virginia and Department of Interior, Washington, D. C., computer charges for use of the mainframes can be reduced. As a consequence, estimated telephone toll charges associated with the remote transmission of data may drop from approximately $\$ 10,000$ in fiscal year 1979 to about $\$ 2,000$ by fiscal year 1983 .

The New Mexico District Data $100 / 78$ terminal was transferred to the Louisiana District in September 1979. Lease and maintenance costs for this terminal were approximately $\$ 21,000$ per year. Transfer of the district file management and programming system (now operating under OMNIANA) from the Kirtland Air Force Base computers to the Harris minicomputer Vulcan System, will save about $\$ 20,000$ in computer charges per year beginning in fiscal year 1980 . A 10 percent savings in computer charges on the USGS Reston system is forecast because of the minicomputer's ability to preprocess files formerly sent to Reston as raw data. Reduced use of outside computer facilities will enable the New Mexico District to return to the vendor a Univac Model 1810 keypunch machine and to appreciably reduce FTS data transmission telephone charges beginning in fiscal year 1980.

Equipment to transfer data from 16 channel paper tape to the minicomputers is scheduled for delivery by Mitron Corporation in early 1980 . The edited data can then be sent via RJE to the computer in Reston. When this system is functional Bell 202 modems currently being used to transmit data will be returned to the telephone company.

The analysis indicates that the cost of leasing and maintaining the two test minicomputer systems can be recovered within the 5 year contract period. The approximate total amount that will be paid by the government for the equipment now installed at each site will approach $\$ 325,000$. The computed 5-year savings (1980-1984) discounted to present value are $\$ 316,000$ to $\$ 349,000$.

The managers in both district offices now believe that the equipment costs (excluding maintenance) can be recovered in about 3 years. The estimated savings shown in Tables 15 and 16 are based upon a 15 percent to 20 percent estimated reduction in previous computer-related analysis costs due to installa- 
tion of the minicomputer equipment. Reassessment by project leaders in both districts within the last 2 months indicates that actual manpower savings will probably approach 50 percent. In a memorandum to the record, D. L. Hart, WRD District Office New Mexico, (Figure 3) pointed out that the actual savings of $\$ 20,006$ for data conversion in his project far exceeded his initial estimates. 
VIII. Proposed Implementation Plan of Distributed Information Processing throughout Water Resources Division.

\section{A. Background}

"Water Resources Division of the U.S. Geological Survey is the principal Federal water-data agency... The major use of ADP and computers in the Division is for managing, processing, storing, retrieving, publishing and disseminating large volumes of data in the National Water Data System. In addition, an intense research and development program is conducted for the design... of new software and hardware unique to the hydrologic discipline and the development of computerized models for the analysis, interpretation and simulation of hydrologic and hydrogeologic system." (LRADP Plan, 1979, pg. 1)

The work outlined in the statements above is performed by employees located in the National Headquarters, the four regional offices, the 46 district offices, the two central laboratories, and in over 200 project, subdistrict, and field offices throughout the United States. It is accomplished on a large variety of computers. Included are the USGS IBM and MULTICS computers, Control Data supercomputers, diverse computers available at Universities and other Federal agencies and a few dedicated minicomputers. Most WRD users submit batch jobs to the host computer via remote job entry (RJE) terminals. Others use low-speed asynchronous terminals to run jobs interactively on the hosts. Some use programmable calculators with a variety of peripheral equipment to make standalone calculations and data manipulations.

On this diverse hardware, WRD employees necessarily use a wide assortment of applications software. Programs to maintain the national water data bases have been written and documented by the headquarters staffs. The National Water Data Storage and Retrieval System (WATSTORE) utilizes both Data Base Management (DBMS) software and numerous WRD-programmed applications. WATSTORE provides a framework within which the national data files for Surface Water, Water Quality, Ground Water, Sediment, and Water Use can be maintained. WATSTORE runs are usually submitted from RJE terminals as jobs for overnight or weekend turnaround. Data input is fixed format. They are run against programs, within which users may select options to produce the desired results. These programs must be very general to allow for the variety of needs of the users. Other applications, written and maintained by computer users in the field for their unique needs, may be completely specific and of interest only to that one user. These programs will be tallored to the hardware and system software available at local computers. As such, they often have little transfer value without extensive reprogramming and documentation.

Other important computer applications are those written by the WRD research staff. These programs often provide state-of-the-art numerical techniques for district project personnel to apply to hydrologic problems. 
These programs generally are developed on the USGS IBM computers in Reston and documentation is published describing the input and output procedures for the IBM systems. Some project users run the code on the Reston systems, while others adapt the code to run on locally available computers that may be more suitable to the computational nature of the programs.

The daily business of WRD requires heavy computer use. This requirement continues to grow each year. Water data and their analysis and interpretation are essential to the national management of water resources. The data bases become more extensive, the modeling activity becomes more critical to decision-making, and the need for faster access to computer-based information increases.

Data entry and file accuracy are the responsibility of each originating office within WRD. Currently, file maintenance is performed from field offices in batch mode, generally using punched cards and remote job entry (RJE) terminals. These terminals were installed in the district offices during the period 1972-1976 specifically to provide online support for WATSTORE activities. The RJE terminals are also used to communicate with various host computer processors to support the project activity. Mainframe hosts include those from virtually every manufacturer. Usually, computers available within the communities where district offices are located are accessed. Some supercomputers are accessed by districts for large-scale modeling. Each district is responsible for modifying and maintaining programs which run on machines other than the USGS computers.

Doug Posson, Computer Systems Analyst, New Mexico District designed specifications for one general-purpose minicomputer system in 1975 which would functionally replace the New Mexico District RJE terminal and provide some stand-alone computing. The Interior Department office of ADP and Telecommunications Management returned the proposal and suggested that WRD might analyse a division-wide installation of minicomputers. This study commenced in April 1976 when Jess McNellis contacted all district offices to ascertain their computational needs, their manpower and budgetary restraints and their desire for in-house computer support. The study results demonstrated strong support for the installation of minicomputers in a network of decentralized systems.

Several important concepts included in this study were included in an RFP issued in October 1977 which resulted in a contract award to Harris Corporation and the installation of S125 minicomputer systems in the Kansas and New Mexico Districts.

This report recognized that any minicomputer systems obtained by the Division should be within the acquisition and use range of both small districts and large subdistricts and should be upgradable to meet the needs of large districts as well. Therefore, the necessity was recognized to specify 
an operating system that would be the same at all minlcomputer installations in the Division. With such operating system, software developed at one WRD site would be able to run at any other WRD site, subject only to limitations in memory and type of peripheral equipment at a specific site. For effective use, any minicomputer system would have to be capable of concurrently serving as a remote job entry terminal (RJE), support time-sharing terminals (TSO), and be a stand alone processor (SAP) performing batch and interactive job processing.

\section{B. WRD Computing Requirements}

The Water Resources Division is required to develop, update, and maintain a variety of water data files at National Headquarters. District programs, primarily cooperative programs, are the source of data for the data bases. Data users require that their data be maintained, updated, and accessible at a local level. These data are utilized more frequently by the originating project personnel than they are nationally. Hence, our present system is not sufficient. Data processing, for the file maintenance and for specific applications, requires timely, cost-effective access. These files are growing rapidly in units per file and in number of files.

Interactive data entry, text editing, and graphics are required in district $\mathrm{ADP}$ activites to efficiently carry out district programs. Usage in these three areas will be extensive in the districts with minicomputers. District activities also include large-scale mainframe modeling of hydrologic processes with numerical and statistical techniques. Data calibration for the large mainframe models requires extensive manipulation that can be done most effectively independent of computer mainframes.

1. The minicomputers must be remote job entry terminals, time sharing terminals, and stand alone processors performing batch and interactive job processing. These required capabilities are detailed below.

a. Remote Job Entry (RJE) -- will be as required by the individual offices. Computers to be accessed include:

1) IBM 360 and 370 series

2) Univac 1100 series

3) $\mathrm{CDC}$ Cyber 70,6600 , and 7600 series

4) Burroughs 3500,5500 , and 6700 series

5) Honeywe11 600,6000 , and 60 series

6) DEC 10 series

7) Any other required by any office specified in a subsequent RFP. 
b. Stand alone processor (SAP)

1) Must be able to compile, load, and execute FORTRAN, BASIC, and Assembler programs at all installations, with $\mathrm{COBOL}$ an option for offices that buy it.

2) Must perform batch job processing from the central site and from terminal input sites.

3) Must perform interactive job processing from the central site, from local in-house direct wired, CRT and teletype sites, from external, phone access, CRT and teletype sites.

4) Must support data entry activities, key to disk type.

5) Must interface with MITRON MPTR-16 or equivalent at a11 installations.

6) Depending on the office, must:

a) behave as a host computer to multiple TS terminals,

b) peform word processing and text editing

c) perform unit record $I / O$, spooled $I / O$

d) perform sort/merge of multi files

e) support a graphics package via FORTRAN and BASIC

f) support available data base management systems (DBMS)

g) support random and sequential file structures

c. Peripheral support -- as required by individual offices, and includes:

1) disks

2) card readers

3) line printers

4) $\mathrm{CRT}^{\prime} \mathrm{s}$

5) magnetic tapes

6) card punch

7) plotter

8) digitizer

9) OCR

10) teletype terminal

11) support presently owned Data 100 peripherals

2. Planned Agency Procurement Request. Will come with next stage. (Division leve1)

3. Information on Procurement Method. Procurement will be by a Request for Proposal (RFP). Each RFP will be evaluated for complete responsiveness to all mandatory requirements and a live demonstration of mandatory items will be required. The lowest priced, best and final offer will be accepted. 
4. Management of Project. Water Resources Division, USGS

5. Location. District and subdistrict offices around the country.

6. Action to date. Minicomputers were acquired in the Kansas and New Mexico District offices. Sections I through VII of this report discuss the results of tests conducted in these two districts.

7. Milestone. Based on data from a previous feasibility study by J. M. McNellis, 1976 , a minimum of 50 and a maximum of 80 systems will be required. 
The table below is an estimated timetable for acquisition of the minicomputer systems. The cumulative numbers of minicomputers are 30 in 1 year, 44 in 3 years, and 80 in 5 years. These figures indicate a substantial commitment to minicomputers by the WRD.

\begin{tabular}{|c|c|c|c|}
\hline \multirow[b]{2}{*}{ District } & \multicolumn{2}{|c|}{$\begin{array}{l}\text { Based On } \\
\text { District } \\
\text { Responses }\end{array}$} & \multirow{2}{*}{$\begin{array}{l}\text { Estimated } \\
\text { By Study } \\
\text { Personne1 } \\
\begin{array}{c}3-5 \\
\text { Years }\end{array}\end{array}$} \\
\hline & $\begin{array}{l}\text { Within } \\
\text { First } \\
\text { Year }\end{array}$ & $\begin{array}{c}1-3 \\
\text { Years }\end{array}$ & \\
\hline Alabama & 1 & & 1 \\
\hline Alaska & 1 & & 1 \\
\hline Arizona & & & 2 \\
\hline Arkansas & 1 & & \\
\hline California & 2 & 1 & 1 \\
\hline Colorado & 1 & 1 & 2 \\
\hline Connecticut & & & 1 \\
\hline Florida & 2 & 2 & 1 \\
\hline Georgia & & & 1 \\
\hline Hawaii & & & 1 \\
\hline Idaho & & & 1 \\
\hline Illinois & & & 1 \\
\hline Indiana & & & 1 \\
\hline Iowa & 1 & & \\
\hline Kansas & 2 & 1 & \\
\hline Kentucky & 1 & 1 & \\
\hline Louisiana & & & 1 \\
\hline Maryland & & 2 & \\
\hline Michigan & 1 & & \\
\hline Minnesota & 1 & & \\
\hline Mississippi & 1 & & \\
\hline Missouri & & & 1 \\
\hline Montana & & & 1 \\
\hline Nebraska & & & 1 \\
\hline Nevada & 1 & & \\
\hline New England & 1 & & 1 \\
\hline New Jersey & 1 & & \\
\hline New Mexico & 1 & & 1 \\
\hline New York & 1 & 1 & 1 \\
\hline North Carolina & & & 1 \\
\hline North Dakota & 1 & 1 & \\
\hline Ohio & 1 & 1 & \\
\hline Oklahoma & 1 & & \\
\hline Oregon & 1 & & 1 \\
\hline Pennsylvania & 1 & & 1 \\
\hline
\end{tabular}


(continued)

\begin{tabular}{|c|c|c|c|}
\hline \multirow[b]{2}{*}{ District } & \multicolumn{2}{|c|}{$\begin{array}{l}\text { Based On } \\
\text { District } \\
\text { Responses }\end{array}$} & \multirow{2}{*}{$\begin{array}{c}\text { Estimated } \\
\text { By Study } \\
\text { Personne1 } \\
\\
3-5 \\
\text { Years } \\
\end{array}$} \\
\hline & $\begin{array}{l}\text { Within } \\
\text { First } \\
\text { Year } \\
\end{array}$ & $\begin{array}{c}1-3 \\
\text { Years } \\
\end{array}$ & \\
\hline Puerto Rico & & & 1 \\
\hline South Carolina & & & 1 \\
\hline South Dakota & & 1 & \\
\hline Tennessee & & & 1 \\
\hline Texas & 1 & & 4 \\
\hline Utah & 1 & 1 & 2 \\
\hline Virginia & & & 1 \\
\hline Washington & 1 & 1 & 1 \\
\hline West Virginia & & & 1 \\
\hline Wisconsin & 1 & & \\
\hline Wyoming & 1 & & \\
\hline TOTAL & 30 & 14 & 36 \\
\hline
\end{tabular}




\section{Alternatives}

To meet WRD data processing needs, six different implementation plans were considered. The plans range from a continuation of the present system to establishment of integrated information systems at district offices. Consideration was given to the advantages and disadvantages of each.

\section{Continuation of current system.}

The current operation is an advance over previous methods. It is based on Data 100 Model 70 and Model 78 remote batch terminals installed in 1972 through 1975 in most WRD district offices. These terminals access IBM 370 computers in Reston as well as other mainframe computers. In addition to the Data 100 equipment, approximately 12 Datapoint series 1100 terminals have been purchased for use in district and subdistrict offices. These terminals are equipped with floppy disk drives, a small central processor and an interactive CRT screen. Besides being able to transmit and receive remote batch jobs, it is possible to pre-edit data on the Datapoint machines.

The principle deficiency with the Data 100 and Datapoint terminals is that the RJE mode does not allow district offices the flexibility required to meet increasing workloads efficiently. There is no way to do text editing, and no way to do pre-editing of initial data using the Data 100 terminals. There is also no method for running small and tedious jobs without incurring mainframe charges for accessing, mounting tapes, etc., that are much greater than the computing cost associated with such jobs.

Dissatisfaction with the current system has been evident in the proliferation of a variety of intelligent terminals (including the Datapoint systems), smal1 stand alone scientific computers, and word-processing machines. These procurement efforts have been aimed at increasing data processing capability and the ability to interface with other computing equipment.

\section{Improvement of current system.}

Both central site and remote terminal facilities should be studied in any effort to improve the current data processing system. An investigation of ways to achieve better response time from the central computers should be pursued. From the district office viewpoint, the lease or purchase of intelligent terminal equipment should be considered. Such equipment should at least offer either an off-line or on-line file storage facility and a text editing capability similar to the Datapoint 1100 series machines.

If improvement in the overall response time of the central computers could be accomplished, then costs would be reduced and efficiency increased. At the field level, the acquisition of machines with file storage and text editing capability would obviously greatly enhance the current mode of operation. 
There are many disadvantages, however, to undertaking an improvement program of this nature especially if pursued by acquiring more sophisticated equipment at the local level. Unless a coordinated procurement is undertaken, the acquisition of intelligent terminal equipment would lead to many incompatibilities. If a variety of terminals were obtained, interfacing and communicating between them would probably be very difficult or impossible. Since most machines in this class use non-standard operating systems and have no high-level language capability with the possible exception of the BASIC language, program transportability would not be achievable.

Intelligent terminals have limited stand alone computing power. They could not be used effectively to support the present stand alone computing needs of many WRD district offices. For example, there is a need to develop and execute certain applications at the local level and a need to preedit hydrologic simulation model input prior to transmission of the data to the mainframe computers. These tasks are beyond the capability of small intelligent terminals.

\section{Major modification of current system.}

Steps have been taken by the Bureau to join the ARPANET and TYMNET computer networks. This service could provide a means for increasing the effectiveness of the Survey's computer systems. To be truly effective, however, the IBM 370 mainframes and the Honeywell MULTICS systems must be interconnected to permit exchange of information. If this could be accomplished, the Data 100 and Datapoint series 1100 terminals could be used for RJE batch service and interactive asynchronous terminals operating through the MULTICS systems could be used to access mainframe programs and data or vice versa. Various interactive terminals, ranging from impact printing terminals to intelligent CRT devices, are suitable for connection to the MULTICS systems.

Users would be served by a more flexible computing system if this option were implemented. By integrating the two systems, users would be able to store, retrieve, or otherwise manipulate their data from one system to the other using either the RJE batch equipment or an interactive terminal. Additionally, if both systems were interconnected through national computer networks, then users presumably could communicate with all other offices connected to the same networks.

Unfortunately, most of the advantages inherent in distributed processing are lost through implementation of this option. First, the principal drawback to this plan is the lack of stand alone computing power--one of the primary requirements of WRD district and subdistrict offices. Reliable computing power is needed at the district sites for storage and processing of local information. Second, all interactive processing would be confined to speeds of 30 to 120 characters per second transmitted over dial up asynchronous telephone lines. As more and more terminals were added to the network, performance would degrade unless the central site equipment were upgraded to meet 
the computing demands. Third, the job control language (JCL) necessary to use an integrated IBM 370 mainframe and Honeywell MULTICS system may be at least an order of magnitude more complex than the existing JCL for either computer. This would tend to discourage the naive user from using the system and add additional complexity to be mastered by more sophisticated users. Fourth, integrated word processing would not be possible with a diversity of interactive terminals and stand alone word processing equipment not compatible to the data processing network.

As of December 1979, file incompatibilities continued to exist between the IBM 370 and MULTICS equipment. Tapes were still being handcarried from one system to the other. It is obviously not a trivial task to interface the two machines. This issue nevertheless would have to be resolved before implementation of this option could be considered.

4. Installation of hierarchical distributed processing system.

A distributed processing system designed within the organizational structure of WRD might have merit. For example, large minicomputers could be installed in each of the four WRD regional offices. Each region, however, would probably have special requirements which would have to be considered in the design.

The Southeast Region office in Atlanta, Georgia, has jurisdiction over nine district offices including the Puerto Rico office. With the exception of the San Juan, Puerto Rico, office, all offices might be served via RJE devices from a single machine located in Atlanta. The situation in the Western Region, headquarters at Menlo Park, California, is similar in that a single large minicomputer located there could serve the six district offices associated with that region. The district offices in Alaska and Hawaii, also members of the Western Region group would probably require inhouse stand alone computing facilities due to their distance from the central office in Menlo Park.

The two other WRD regional offices, Central Region, Lakewood, Colorado and Northeast Region, Reston, Virginia, are much larger. Fifteen district offices are affiliated with the Central Region and 14 offices with the Northeast Region. At least two machines in each of these regions would be needed to provide effective service to all districts.

The six or more large minicomputers located within the four WRD regional areas might be linked via synchronous communication lines to the central mainframes in Reston. Typically, intelligent terminals located in district offices would run applications and update data bases residing on the regional machines. In turn, applications running on the regional machines would be used to transfer update information to the national data bases stored on the Reston mainframe computers. 
In contrast with previous alternatives, the hierarchical distributed processing scheme offers the advantage of shorter communication lines. RJE traffic could be carried via star networks from the district offices to the large regional minicomputers. Communication between the regional minicomputers and the Reston mainframe computers could be maintained by connecting them in a ring type network.

Reliability would possibly be improved. If a regional minicomputer were inoperative, traffic could be rerouted to other regional machines not operating at full capacity or directly to the computers in Reston.

Since successful operation of this alternative is dependent on the communication linkages from the districts to the mincomputers, many limitations are imposed on the users as a result. The district users are entirely dependent on the regional computer centers for support. Little or no stand alone processing capability would be available where it is needed most--in the district office. It would be troublesome to interface word processing equipment to the RJE or intelligent interactive terminals so that word processing files could be transmitted to other districts or to the regional and national centers.

5. Installation of modified hierarchical distributed processing system.

Instead of establishing regional centers as in the previous alternative, two or more district or subdistrict offices could share the resources of a single minicomputer. Implementation of this alternative would require the lease or purchase of from 20 to 25 minicomputers depending on how many district offices shared each machine.

Machines could be located to minimize communication line lengths and costs. One possible arrangement would be to link RJE equipment in the neighboring district office or offices with the shared minicomputer via dial-up telephone lines operating at synchronous data transmission speeds. In situations where RJE traffic was light, for example at small subdistrict offices, communication via asynchronous speed dial-up lines might suffice. A dial-up synchronous speed line would be needed to link each minicomputer with the mainframe computers in Reston.

This plan has the advantage of bringing computing power within grasp of more users. Users in districts where minicomputers were installed would be able to benefit most. As expertise of these users developed, they could share their knowledge and assist with application development in neighboring district and subdistrict offices.

Districts may have difficulty resolving the management problems associated with sharing a minicomputer. However, the primary disadvantage of this approach is that it does not offer stand alone computer power to all users. 


\section{Establishment of integrated information systems.}

The option which best meets the needs of WRD district

offices is implementation of integrated information systems. WRD needs include local stand alone batch and interactive processing along with remote job entry capability. All three modes must be able to operate concurrently. A data base management system is required for storage and retrieval of data collected locally. CRT interactive terminals direct wired to the minicomputer are required with the capability of providing service at speeds up to 960 characters per second. Intelligent terminals in subdistrict offices need to be linked with the district machine via asynchronous dial-up telephone lines.

Each system should be capable of being assembled from a large family of compatible processors and peripherals to meet the needs and budget restrictions of all WRD district and subdistrict operations. At least 64 communication ports per machine should be available for districts having a need for connecting a wide variety of peripherals.

With such systems installed in district offices, many labor intensive processes could be automated at the local leve1. Word processing, data entry, text editing, application program development, debugging and execution, hydrologic-simulation modeling, and automatic updating of the national data base are among some of the tasks which could be performed by district minicomputers. The tests in Lawrence, Kansas, and in Albuquerque, New Mexico, have demonstrated that these requirements can be met cost effectively with minicomputers.

The advantages of distributed information processing are many and varied. Some of the most obvious benefits include increased user control, increased responsiveness, quick access to local data bases, reduced communication costs, and in general, costs more readily related to function. At this point, integrated information systems appear to offer the most straightforward approach to current computing requirements in WRD.

\section{Effects on Central Computer Operation}

Installation of minicomputers in WRD district offices will change the way the central computer system has traditionally been used by WRD personnel. Application oriented use will probably diminish; processing related to file management, maintenance and archiving will substantially increase.

For example, one of the current major uses of the central computer is to edit and preprocess data. That activity will be transferred to district minicomputers and the updated files can then be transmitted to the central computer where they can be merged with the national data bases. This kind of application at the central site will probably increase as the network of minicomputers expands to district, subdistrict, and WRD cooperator offices and as 
large numbers of new users begin supplying input to the system. As users discover the capabilities and advantages of interactive computing, some applications now running on the central machine may be transferred to the minicomputers.

\section{E. Effects on National Networks}

\section{Effect of Minicomputers on WATSTORE}

The placement of minicomputers in district offices will have a marked effect on the National Water Data Storage and Retrieval System (WATSTORE). Eventually, the data editing and data processing functions of WATSTORE will be off-loaded to the district office minicomputers. However, the Automatic Data Section, WRD, plans to maintain a national suite of WATSTORE computer programs that execute on the minicomputers to avoid duplication of effort. It is also planned to maintain the WATSTORE data bases on a national level with weekly updates being transmitted by the minicomputers. For the Ground-Water Site-Inventory data base (managed by SYSTEM 2000) only pre-edit functions can be performed on the minicomputers because of the necessity to validate certain update transactions with information already stored in the data base. In addition, an ADP Inventory System, which is a SYSTEM 2000 data base, has been implemented so that user developed software may be shared among districts.

\section{Effect of Minicomputers on NWUDS}

The National Water Use Data System (NWUDS) is a national cooperative program working under agreements with 45 State governments and Puerto Rico to develop a national water use data system. The national system will be the aggregation of data stored in general State water use systems developed and implemented by the individual States.

Minicomputers in the district offices will quite likely accelerate the development of State level data storage systems. The storage of site specific data, such as an industry, a home, or a water company, is the responsibility of the state cooperator. The installation of a minicomputer in the district may result in many of the States using this hardware to store their site specific data. The national system will be updated by the minicomputers on a systematic basis.

\section{Effect of Minicomputers on NAWDEX}

The placement of minicomputers in district offices should have little effect on the National Water Data Exchange (NAWDEX) program. NAWDEX maintains three large-scale data bases: the Water Data Sources Directory, the Master Water Data Index, and the Master Ground Water Data Index. All data bases were developed using the SYSTEM 2000 data base management system, thereby preventing their offloading to minicomputers. Also, NAWDEX maintains information 
on an interagency basis which is accessible through 59 assistance centers and several other outside organizations. These data bases require a centralized repository; their structures and designs are not currently amenable to a distributed data base system.

Potential minicomputer applications for NAWDEX at the district level include 1) the maintenance in local files of WRD funding and project information for sites within each district with periodic updates to the national data base, 2) offline printing of information reports of a repetitive nature from archived tapes or disk files, 3) offline plotting of sitelocation maps, and 4) a pre-edit of input to the NAWDEX data bases. Only preedit functions can be performed because of the necessity to validate certain update transactions with information already stored in the data bases.

\section{F. Recommendations}

In view of the enthusiastic acceptance by users of the test machines in WRD District Offices in Kansas and New Mexico, the cost effectiveness of the installed equipment, the probable minimal effects on the central computer operation and national networks, and the continuing movement in the computer industry to market innovative products at lower cost, it is recommended that WRD proceed to procure integrated information system (option 6) capable of:

1. Conventional data processing in batch, interactive, and remote job entry modes.

2. Sophisticated work and text processing.

3. Report preparation capability, including interface to typesetting equipment.

4. Support of a Data Base Management System package.

5. The capability of communicating with any other WRD integrated information system to allow teleconferencing, electronic mail service, and the sharing of system and application programs.

6. The capability of being interfaced to data gathering devices both in the field and in the office. Such devices include laboratory instruments, portable point-of-entry, data-logging equipment, data-conversion equipment, and hydrologic field recording equipment.

7. Each integrated information system must be capable of running all tasks described above concurrently.

8. Each system must be capable of being assembled from a large family of compatible processors and peripherals to meet the needs and budget restrictions of each WRD district and subdistrict operation. 
APPENDIX 
44 


\section{Table 1}

\section{Data Processing Cost Comparison Summary}

WRD District Office, Kansas

Onsite Leased Minicomputer

$\underline{\text { Year }}$

Savings (Undiscounted)

Savings (*Discounted)

FY 1980

$\$ 40,154$

$\$ 36,504$

FY 1981

$\$ 77,412$

$\$ \quad 63,977$

FY 1982

$\$ 91,494$

\$ 68,741

FY 1983

$\$ 116,222$

$\$ 79,381$

FY 1984

$\$ 162,120$

$\$ 100,664$

Total

$\$ 487,402$

$\$ 349,467$

*Discounted present value at 10 percent 
Table 2

Data Processing Cost Comparison Summary

WRD District office, New Mexico

\section{$\underline{\text { Year }}$}

FY 1980

FY 1981

FY 1982

FY 1983

FY 1984

Total
Savings (Undiscounted)

$\$ \quad 42,062$

$\$ 72,646$

$\$ 81,749$

$\$ 99,644$

$\$ 143,027$

$\$ 439,128$
Savings (*Discounted)

$\$ \quad 38,238$

$\$ \quad 60,038$

$\$ \quad 61,419$

$\$ \quad 65,058$

$\$ 88,809$

$\$ 316,562$

*Discounted present value at 10 percent 


\section{Table 3}

Data Processing Cost Comparison FY 79

WRD District Office, Kansas

Remote Batch Job Terminal

Harris S125 Computer System

(Initial configuration

lease and maintenance costs)

Data $100 / 78$

(Lease and maintenance costs)
Onsite Leased Minicomputer

0

$\$ 68,161$ (Jan. 15, 1979 through

Sept. 30, 1979)

$\$ 23,480$ (Oct. 1, 1978 through

July 31, 1979)

Honeywe11 66/60 Univ. of

Kansas, Lawrence, Kansas

$\$ 30,000$

$\$ 10,000$

(Computer use charges)

IBM 370 USGS, Reston, VA and $\$ 20,500$

$\$ 22,000$

Ite1 AS5 Dept. of Interior,

Washington, D.C.

(Computer use charges)

Telephone toll charges

$\$ 9,940$

$\$ 9,940$

Be11 208B modem ( 4800 bps)

and Be11 201C modem (2400

$\$ 2,460$

$\$ 2,460$

bps)

(Lease cost)

Be11 202 modem

(Interfaced to Mitron

$\$ 300$

0

paper tape reader. Lease

cost)

Tota1 expenses

$\$ 91,376$

$\$ 136,041$

Personnel savings

0

\$ 46,700 (Jan. 15, 1979

through

Sept. 30, 1979)

Net expenses

$\$ 91,376$

$\$ 89,341$

Total annual savings

$\$ 2,035$ 
Table 4

Data Processing Cost Comparison FY 80

WRD Distrist office, Kansas

Remote Batch Job Terminal Onsite Leased Minicomputer

Harris S125 Computer System

0

$\$ 91,825$

(Initial configuration

lease and maintenance costs)

Data $100 / 78$

(Lease and maintenance costs.

$\$ 30,430$

0

Includes $8 \%$ annual increase)

Honeywel1 66/60 Univ. of Kansas,

$\$ 30,000$

$\$ 5,000$

Lawrence, Kansas

(Computer use charges)

IBM 370 USGS, Reston, VA and

$\$ 22,550$

$\$ 20,000$

Itel AS5 Dept. of Interior,

Washington, D.C.

(Computer use charges.

Includes $10 \%$ annual increase)

Telephone toll charges

$\$ 9,940$

$\$ 6,630$

Be11 208 modem ( 4800 bps) and

$\$ 2,460$

$\$ 2,460$

Be11 201C Modem (2400 bps)

(Lease cost)

Bel1 202 modem

(Interfaced to Mitron paper

tape reader. Lease cost)

Tota1 expenses

Personnel savings

(Includes $7 \%$ annual increase)

Net expenses

Total annual savings
$\$ 95,680$

$\$ \quad 300$

0

$\$ 95,680$

$\$ 125,915$

0

\$ 70,389

$\$ 55,526$

$\$ 40,154$ 


\section{Table 5}

\section{Data Processing Cost Comparison FY 81}

WRD District Office, Kansas

Remote Batch Job Terminal

0

$\$ 32,864$

$\$ 30,000$

Honeywe11 66/60 Univ. of Kansas,

Lawrence, Kansas

(Computer use charges)

IBM 370 USGS, Reston, VA and

Itel AS5 Dept. of Interior,

Washington, D.C.

(Computer use charges.

Includes $10 \%$ annual increase)

Telephone toll charges

Be11 208B modem ( 4800 bps) and

Bell 201C modem (2400 bps)

(Lease cost)

Be11 202 modem. (Interfaced to Mitron paper tape reader.

Lease cost)

Total expenses

Personnel savings

(Includes $7 \%$ annual increase)

Net expenses

$\$ 100,369$

Total annual savings
$\$ 22,957$

Onsite Leased Minicomputer

$\$ 70,813$

$\$ \quad 5,000$

$\$ 15,000$

$\$ \quad 5,000$

$\$ 2,460$

$\$ 98,273$

$\$ 75,316$

$\$ 77,412$ 
Table 6

Data Processing Cost Comparison FY 82

WRD District Office, Kansas

Remote Batch Job Terminal Onsite Leased Minicomputer

Harris S125 Computer System

(Initial configuration

lease and maintenance costs)

Data $100 / 78$

(Lease and maintenance costs.

Includes $8 \%$ annual increase)

Honeywel1 66/60 Univ, of Kansas,

Lawrence, Kansas

(Computer use charges)

IBM 370 USGS, Reston, VA and

Itel AS5 Dept. of Interior,

Washington, D.C.

(Computer use charges.

Includes $10 \%$ annual increase)

Telephone toll charges

Bel1 208B modem ( 4800 bps) and

Be11 201C modem (2400 bps)

(Lease cost)

Be11 202 modem. (Interfaced to Mitron paper reader.

Lease $\cos t$ )

Total expenses

Personnel savings

(Includes $7 \%$ annual increase)

Net expenses

$\$ 105,479$

$\$ 27,286$

$\$ 14,000$
$\$ 105,479$

0

$\$ 94,573$

$\$ 80,588$

$\begin{array}{ll}\$ 9,940 & \$ 3,300 \\ \$ 2,460 & \$ 2,460\end{array}$

$\$ 300$

0

$\$ 13,985$

$\$ 91,494$

Total annual savings 


\section{Table 7}

\section{Data Processing Cost Comparison FY 83 \\ WRD District Office, Kansas}

Remote Batch Job Terminal

0

Harris S125 Computer System

(Initial configuration

lease and maintenance costs)

Data $100 / 78$

(Lease and maintenance costs.

$\$ 38,332$

0
Onsite Leased Minicomputer

$\$ 62,593$

Includes $8 \%$ annual increase)

Honeywe11 66/60 Univ. of Kansas,

$\$ 30,000$

$\$ \quad 4,000$

Lawrence, Kansas

(Computer use charges)

IBM 370 USGS, Reston, VA and

$\$ 30,014$

$\$ 10,000$

Ite1 AS5 Dept. of Interior,

Washington, D.C.

(Computer use charges.

Includes $10 \%$ annual increase)

Telephone toll charges

$\$ 9,940$

$\$ 2,000$

Be11 208B modem ( 4800 bps) and

$\$ 2,460$

$\$ 2,460$

Be11 201C modem (2400 bps)

(Lease cost)

Bell 202 modem. (Interfaced to

Mitron paper tape reader.

Lease $\cos t$ )

Total expenses

$\$ 111,046$

0

Personnel savings

(Includes $7 \%$ annual increase)

Net expenses

$\$ 111,046$

Total annual savings

$(\$ 5,176)$

$\$ 116,222$
$\$ 81,053$

$\$ 86,229$ 
Table 8

Data Processing Cost Comparison FY 84

WRD District Office, Kansas

Remote Batch Job Terminal Onsite Leased Minicomputer

Harris S125 Computer System

(Initial configuration

maintenance cost only)

Data $100 / 78$

(Lease and maintenance costs.

Includes $8 \%$ annual increase)

Honeywe11 66/60 Univ. of Kansas,

Lawrence, Kansas

(Computer use charges)

IBM 370 USGS, Reston, VA and

Itel AS5 Dept. of Interior,

Washington, D.C.

(Computer use charges.

Includes $10 \%$ annual increase)

Telephone toll charges

Be11 208B modem ( 4800 bps) and

Be11 201C modem (2400 bps)

(Lease cost)

Bel1 202 modem. (Interfaced to

Mitron paper tape reader.

Lease cost)

Total expenses

Personnel savings

(Includes $7 \%$ annual increase)

Net expenses

Total annual savings
0

$\$ 28,800$
$\$ 117,115$

0

$\$ \quad 4,000$

$\$ 33,015$

$\$ 10,000$

$\$ 2,000$

$\$ 9,940$

$\$ 2,460$

$\$ 2,460$

$\$ \quad 300$

0

$\$ 47,260$

$\$ 92,265$

$\$ 117,115$

(\$ 45,005)

$\$ 162,120$ 
Table 9

Data Processing Cost Comparison FY 79

WRD District Office, New Mexico

Remote Batch Job Terminal Onsite Leased Minicomputer

Harris S125 Computer System

(Initial configuration lease and maintenance costs)

Data $100 / 78$

(Lease and maintenance costs)

CDC 7600 Kirtland AFB,

Albuquerque, NM

(Computer use charges)

IBM 370 USGS, Reston, VA

(Computer use charges)

Itel AS5 Dept. of Interior, Washington, D.C.

(Computer use charges)

Univac 1810 keypunch

(Lease cost)

FTS charges

Leased telephone lines

Be11 208B modem (4800 bps)

(Lease cost)

Be11 202 modem

(Interfaced to Mitron paper

tape reader. Lease cost)

Statistical multiplexer and modems (Amortization of

purchase costs)

Tota1 expenses

Personnel savings

Net expenses

Total annual savings
0

$\$ 21,000$ (Oct. 1, 1978 through

Sept. 30, 1979)

$\$ 37,000$

$\$ 22,000$

$\$ 14,000$

$\$ 12,600$

$\$ 2,400$

$\$ 2,400$

$\$ 3,000$

$\$ 3,000$

$\$ 3,600$

$\$ 3,600$

0

$\$ \quad 500$

$\$ 1,620$

$\$ 1,620$

$\$ \quad 300$

0

0

$\$ \quad 450$

$\$ 82,920$

$\overline{\$ 82,920}$
$\$ 98,970$

$\$ 43,004$ (April 1, 1979

through

Sept. 30, 1979) through

Sept. 30, 1979) through

July 31, 1979) 
Table 10

\section{Data Processing Cost Comparison FY 80 \\ WRD District Office, New Mexico}

Harris S125 Computer System

Remote Batch Job Terminal

(Initial configuration lease 0

Onsite Leased Minicomputer

and maintenance costs)

Data $100 / 78$

$\$ 22,680$

0

(Lease and maintenance costs. Includes $8 \%$ annual increase)

CDC 7600 Kirtland AFB, $\$ 60,000$

$\$ 40,000$

Albuquerque, NM

(Computer use charges)

IBM 370 USGS, Reston, VA

$\$ 15,400$

$\$ 13,860$

(Computer use charges.

Includes $10 \%$ annual increase)

Itel AS5 Dept. of Interior,

$\$ 2,400$

$\$ 1,600$

Washington, D.C.

(Computer use charges)

Univac 1810 keypunch

(Lease cost)

$\$ 3,000$

FTS charges

$\$ 3,600$

$\$ 1,800$

Leased telephone lines

0

$\$ \quad 4,660$

Be11 208B modem (4800 bps)

(Lease cost)

$\$ 1,620$

$\$ 1,620$

Be11 202 modem

$\$ 300$

0

(Interfaced to Mitron paper

tape reader. Lease cost)

Statistical multiplexer and

0

$\$ 3,600$

modems (Amortization of

purchase costs)

Total expenses

$\$ 109,000$

$\$ 158,965$

Personnel savings

(Includes $7 \%$ annual increase)

Total annual expenses

$\$ 42,062$ 
Data Processing Cost Comparison FY 81

WRD District Office, New Mexico

Remote Batch Job Terminal Onsite Leased Minicomputer

Harris S125 Computer System

(Initial configuration lease

and maintenance costs)

0

$\$ 70,813$

Data $100 / 78$

$\$ 24,500$

0

(Lease and maintenance costs.

Includes $8 \%$ annual increase)

CDC 7600 Kirtland AFB,

$\$ 60,000$

$\$ 40,000$

Al buquerque, NM

(Computer use charges)

IBM 370 USGS, Reston, VA

$\$ 16,900$

$\$ 15,250$

(Computer use charges.

Includes $10 \%$ annual increase)

Itel AS5 Dept. of Interior,

$\$ 2,400$

$\$ 1,600$

Washington, D.C.

(Computer use charges)

Univac 1810 keypunch

$\$ 3,000$

0

(Lease cost)

FTS charges

$\$ 3,600$

$\$ \quad 600$

Leased telephone lines

0

$\$ \quad 4,660$

Bell 208B modem (4800 bps)

(Lease cost)

$\$ 1,620$

$\$ 1,620$

Bell 202 modem. (Interface

$\$ 300$

0

to Mitron paper tape reader.

Lease cost)

Statistical multiplexer and

0

$\$ 3,600$

modems. (Amortization of

purchase costs)

Total expenses

$\$ 112,320$

$\$ 138,143$

Personnel savings

0

$\$ 98,469$

(Includes $7 \%$ annual increase)

Net expenses

$\overline{\$ 112,320}$

$\$ 39,674$

$\$ 72,646$

Total annual savings 
Table 12

Data Processing Cost Comparison FY 82

WRD District office, New Mexico

Remote Batch Job Terminal

Data $100 / 78$

(Lease and maintenance costs.

Includes $8 \%$ annual increase)

CDC 7600 Kirtland AFB,

Albuquerque, NM

(Computer use charges)

IBM 370 USGS, Reston, VA

(Computer use charges.

Includes $10 \%$ annual increase)

Itel AS5 Dept. of Interior,

Washington, D.C.

(Computer use charges)

Univac 1810 Keypunch

(Lease cost)

FTS charges

Leased telephone lines

Bell 208B modem ( 4800 bps)

(Lease cost)

Bell 202 modem. (Interfaced

to Mitron paper tape reader.

Lease cost)

Statistical multiplexer and

modems (Amortization of

purchase costs)

Total expenses

Personnel savings

(Includes $7 \%$ annual increase)

Net expenses

Total annual savings
0

$\$ 26,460$

Onsite Leased Minicomputer

$\$ 70,813$

0

$\$ 40,000$

$\$ 18,600 \quad \$ 16,700$

$\$ 2,400$

$\$ 1,600$

$\$ 3,000$

0

$\$ \quad 600$

0

$\$ 4,660$

$\$ 1,620$

$\$ 1,620$

300

0

0

$\$ 3,600$

$\$ 115,980$

$\$ 139,593$

0

$\$ 105,362$

$\$ 115,980$

$\$ 34,231$

$\$ 81,749$ 
Data Processing Cost Comparison FY 83

WRD District office, New Mexico

Remote Batch Job Terminal Onsite Leased Minicomputer

Harris S125 Computer System

0

$\$ 62,593$

(Initial configuration lease and maintenance costs)

Data $100 / 78$

$\$ 28,600$

0

(Lease and maintenance costs.

Includes $8 \%$ annual increase)

CDC 7600 Kirtland AFB,

$\$ 60,000$

$\$ 40,000$

Albuque rque, NM

(Computer use charges)

IBM 370 USGS, Reston, VA

$\$ 20,460$

$\$ 18,400$

(Computer use charges. Includes

$10 \%$ annual increase)

Itel AS5 Dept. of Interior,

$\$ 2,400$

$\$ 1,600$

Washington, D.C.

(Computer use charges)

Univac 1810 Keypunch

(Lease cost)

$\$ 3,000$

0

FTS charges

$\$ 3,600$

$\$ \quad 600$

Leased telephone lines

0

$\$ \quad 4,660$

Bel1 208B modems (4800 bps)

(Lease cost)

$\$ 1,620$

$\$ 1,620$

Be11 202 modem. (Interfaced

to Mitron paper tape reader.

Lease $\cos t$ )

Statistical multiplexer and

modems (Amortization of

purchase costs)

Total expenses

Personnel savings

(Includes $7 \%$ annual increase)

Total annual savings 
Table 14

Data Processing Cost Comparison FY 84

WRD District Office, New Mexico

Remote Batch Job Terminal

Harris S125 Computer System

(Initial configuration

maintenance cost only)

Data $100 / 78$

(Lease and maintenance costs.

Includes $8 \%$ annual increase)

CDC 7600 Kirtland AFB, Albuque rque, NM

(Computer use charges)

IBM 370 USGS, Reston, VA

(Computer use charges.

Includes $10 \%$ annual increase)

Itel AS5 Dept. of Interior,

Washington, D.C.

(Computer use charges)

Univac 1810 Keypunch

(Lease cost)

FTS charges

Leased telephone lines

Be11 208B modems (4800 bps)

(Lease cost)

Be11 202 modem. Interfaced to Mitron paper tape reader.

Lease cost)

Statistical multiplexer and modems. (Amortization of purchase costs)

Total expenses

Personnel savings

(Includes $7 \%$ annual increase)

Net expenses
0

$\$ 22,506$

Onsite Leased Minicomputer

$\$ 29,580$

$\$ 30,888$

0

$\$ 60,000$

$\$ 40,000$

$\$ 20,255$

$\$ 2,400$

$\$ 1,600$

$\$ 3,000$

0

$\$ 3,600 \quad \$ \quad 600$

0

$\$ \quad 4,660$

$\$ 1,620$

$\$ 1,620$

$\$ \quad 300$

0

0

$\$ 3,600$

$\$ 124,314$

$\$ 101,915$

0

$\$ 120,628$

Total annual savings 
Table 15

Estimated Yearly Personnel Cost Savings Resulting from Conversion to Minicomputer in WRD District Office, Kansas

\section{Grade Levels are Step 5}

I. Personnel Cost Savings

A. Basic Data Section

1. Rating table computation

Estimated Time Saved (Months)

Grade Leve1 Cost Savings

6.40

GS-7

0.80

GS-5

$\$ 7,866$

0.43

GS-4

794

381

0.09

GS-3

$\frac{71}{9,112}$

2. Ground water-quality of water network

Estimated Time Saved (Months)

Grade Level

Cost Savings

$$
\begin{array}{ll}
0.17 & \text { GS }-7 \\
0.12 & \text { GS }-4
\end{array}
$$

$$
\begin{aligned}
& \$ 209 \\
& 177 \\
& \hline \$ \quad 386
\end{aligned}
$$

3. Quality of water data input

Estimated Time Saved (Months)

Grade Leve1

Cost Savings

$$
\begin{aligned}
& 2.31 \\
& 0.58
\end{aligned}
$$

GS-5

GS -4

$\$ 2,292$

$\$ \frac{514}{2,806}$

4. Completion of Water Discharge Measurement (Form 9-207)

Estimated Time Saved (Months)

Grade Leve1

Cost Savings

$$
0.58
$$

GS-6

\$ 641

GS-4

$\frac{577}{\$ 1,218}$

5. Ground water site data input

Estimated Time Saved (Months)

Grade Leve1

Cost Savings

$$
2.01
$$

GS-3

$\$ 1,588$ 
6. Primary shift and datum computation

Estimated Time Saved (Months) Grade Level Cost Savings

\begin{tabular}{llr}
0.81 & GS -7 & $\$ \quad 995$ \\
0.35 & GS-3 & \\
& & 277 \\
\hline 1,272
\end{tabular}

7. Peak flow data file

Estimated Time Saved (Months) Grade Level $\underline{\text { Cost Savings }}$

\begin{tabular}{|c|c|c|c|}
\hline 0.05 & GS-11 & $\$$ & 91 \\
\hline 0.09 & GS-6 & & 100 \\
\hline \multirow[t]{2}{*}{0.05} & GS-2 & & 35 \\
\hline & & $\$$ & 226 \\
\hline
\end{tabular}

8. Retrieval of daily values

Estimated Time Saved (Months) Grade Level Cost Savings

$0.24 \quad$ GS $-4 \quad$ \$ 231

TOTAL $\$ 16,821$

B. Hydrologic Investigations Section

1. Surface water projects

a. Rainfall-runoff models

Estimated Time Saved (Months) Grade Level Cost Savings
1.15
GS-12
$\$ 2,507$
0.38
GS-4
$\frac{337}{\$ 2,844}$

b. Flood studies-data input and output editing for culvert and backwater programs

Estimated Time Saved (Months) Grade Level Cost Savings

$$
3.38 \quad \text { GS }-9 \quad \frac{\$ 5,084}{\$ 5,084}
$$

c. Frequency analysis of peak-flow data

Estimated Time Saved (Months) Grade Level Cost Savings
0.29
GS-13
$\frac{\$ \quad 752}{\$ \quad 752}$ 
d. Kansas water budget model

Estimated Time Saved (Months) Grade Level Cost Savings

\begin{tabular}{lll}
0.29 & GS -13 & $\$ 752$ \\
0.29 & GS -4 & 257 \\
\hline & & $\$ 1,009$
\end{tabular}

e. Statistical analysis program

Estimated Time Saved (Months) Grade Level

\begin{tabular}{lll}
0.06 & GS -11 & $\$ \quad 109$ \\
0.12 & GS -4 & \\
\cline { 2 - 2 } & & $\frac{106}{215}$
\end{tabular}

f. Channel geometry-regression, input and editing

Estimated Time Saved (Months) Grade Level $\quad \underline{\text { Cost Savings }}$
1.20
GS-11
$\frac{\$ 2,183}{\$ 2,183}$

g. Computation of annual and carry-over storage requirements

Estimated Time Saved (Months) Grade Level $\quad \underline{\text { Cost Savings }}$

$\begin{array}{rlr}1.04 & \text { GS }-11 & \$ 1,892 \\ 0.35 & \text { GS-4 } & \frac{310}{\$ 2,202}\end{array}$

2. Ground water flow and transport models

a. Verification and checking

Estimated Time Saved (months) Grade Level Cost Savings

\begin{tabular}{rlr}
0.40 & GS-13 & $\$ 1,037$ \\
0.12 & GS-12 & 267 \\
0.40 & GS-9 & 602 \\
\hline & & $\$ 1,901$
\end{tabular}

b. Editing and input of data

$\underline{\text { Estimated Time Saved (months) Grade Level }} \underline{\text { Cost Savings }}$

\begin{tabular}{|c|c|c|c|}
\hline 0.09 & GS -13 & $\$$ & 233 \\
\hline 0.09 & GS- 12 & & 196 \\
\hline \multirow[t]{2}{*}{0.20} & GS-9 & & 301 \\
\hline & & $\$$ & 703 \\
\hline
\end{tabular}


c. We11 hydraulic equations

Estimated Time Saved (months)

Grade Leve1

Cost Savings

0.58
0.58
1.73

GS-13

GS-12

$\$ 1,503$

1,264

GS-9

$\frac{2,602}{\$ 5,369}$

3. Water quality projects

a. Chemical data input and editing

Estimated Time Saved (months)

Grade Leve1 Cost Savings

$$
\begin{aligned}
& 0.06 \\
& 0.46
\end{aligned}
$$

GS-13

GS-9

$$
\begin{aligned}
& \$ \quad 156 \\
& \quad 692 \\
& \hline \$ \quad 848
\end{aligned}
$$

b. Sediment data input and editing

Estimated Time Saved (months) Grade Level Cost Savings

\begin{tabular}{lll}
0.06 & GS -12 & $\$ 131$ \\
0.52 & GS -9 & 782 \\
\cline { 2 - 2 } & & $\$ 913$
\end{tabular}

c. Laboratory applications - Data input, editing, and computation

$\underline{\text { Estimated Time Saved (Months) } \quad \underline{\text { Gade Level }} \text { Cost Savings }}$

$$
0.35
$$

GS-9

GS-3

$$
\begin{array}{r}
526 \\
\$ \quad 458 \\
\hline \$ \quad 984
\end{array}
$$

TOTAL $\$ 25,034$

C. Reports Section

1. Report tracking

Estimated Time Saved (Months)

Grade Level
$\begin{gathered}\text { GS-12 } \\ \text { GS-7 }\end{gathered}$

Cost Savings

0.12

0.12

GS-12
GS-7

$\$ 262$

147
$\$ \quad 409$

TOTAL \$ 409 
D. Administration Section

1. Inventory of control property

Estimated Time Saved (Months)

Grade Leve1 Cost Savings

0.12
0.12
0.17
0.46
0.12
0.69
0.35
0.12
0.23
0.75

GS-15

GS-13

GS-12

GS-11

GS-10

GS-9

GS-8

GS-6

GS-4

GS-3

$\$ \quad 432$

311

371

337

199

1,038

476

133

204

593

$\$ 4,594$

2. Supply inventory and ordering

Estimated Time Saved (Months)

Grade Level

Cost Savings

$$
\begin{aligned}
& 0.46 \\
& 0.87
\end{aligned}
$$

GS-11

GS-4

\$ 837

$\frac{772}{\$ 1,609}$

3. Fiscal Summaries and estimates of authorizations, employee pay, project status, travel, and district budget.

Estimated Time Saved (Months)

Grade Leve1

Cost Savings

$\begin{array}{ll}1.12 & \text { GS-15 } \\ 0.43 & \text { GS-14 } \\ 0.23 & \text { GS-13 } \\ 2.64 & \text { GS-9 } \\ 1.06 & \text { GS-6 } \\ 0.43 & \text { GS-4 }\end{array}$

$$
\begin{array}{r}
\$ 4,036 \\
1,318 \\
596 \\
3,971 \\
1,172 \\
381 \\
\hline 11,474
\end{array}
$$

TOTAL $\quad \$ 17,677$

E. Computer Section

1. Program development and conversion

Estimated Time Saved (Months) Grade Level Cost Savings

1.20

0.69

2.31
GS-13

GS-5

GS-4
$\$ 3,110$ 684

$\frac{2,049}{\$ 5,843}$

TOTAL $\$ 5,843$

Estimated personnel cost savings per year $\$ 65,784$ 
Estimated Yearly Personnel Cost Savings Resulting from Conversion to Minicomputer in WRD District Office, New Mexico

\section{Grade levels are Step 5}

I. Personnel Cost Savings

A. Basic Data Section

1. Surface Water, Project 001 - Reduction of computer costs due to installation of minicomputer

Estimated Time Saved (Months) Grade Level $\quad \underline{\text { Cost Savings }}$

$\begin{array}{rlr}2.5 & \text { GS-12 } & \$ 5,450 \\ 2.0 & \text { GS-11 } & 3,638 \\ 1.5 & \text { GS-9 } & 2,256 \\ 0.3 & \text { GS-8 } & 408 \\ 0.5 & \text { GS-7 } & 614 \\ 1.8 & \text { GS-6 } & 1,991 \\ 0.6 & \text { GS-5 } & 595 \\ 0.2 & \text { GS-4 } & 177 \\ 0.4 & \text { GS-3 } & 316 \\ 0.1 & \text { GS-2 } & 70 \\ & & \$ 15,515\end{array}$

2. Ground Water, Project 002 - Reduction of computer costs due to installation of minicomputer

$\underline{\text { Estimated Time Saved (Months) } \quad \text { Grade Level } \quad \text { Cost Savings }}$
0.7
GS-11
GS-9
$\$ 1,273$
0.4
GS-7
602
0.7
GS-3
860
2.0
$\frac{1,580}{4,315}$

3. Chemical Quality, Project 003 - Reduction of computer costs due to installation of minicomputers

Estimated Time Saved (Months)

Grade Level Cost Savings

1.9

2.0

0.5

0.1
GS- 10

GS-7

GS-5

GS-4
$\$ 3,146$

2,458

496

$\frac{88}{\$ 6,188}$ 
4. Sediment, Project 004 - Reduction of computer costs due to installation of minicomputer

Estimated Time Saved (Months) Grade Level

$\begin{array}{llr}1.5 & \text { GS }-10 & \$ 2,484 \\ 1.0 & \text { GS-9 } & 1,504 \\ 2.2 & \text { GS-4 } & 1,951 \\ & & \$ 5,939\end{array}$

B. Hydrologic Investigations Section

$\$ 31,957$

1. Data activity

a. Reduction of computer costs due to direct data entry and error checking via minicomputer

Estimated Time Saved (Months) Grade Leve1 $\quad$ Cost Savings

\begin{tabular}{rlr}
0.75 & GS -12 & $\$ 1,635$ \\
1.00 & GS-9 & 1,504 \\
1.00 & GS-4 & 887 \\
3.00 & GS-3 & 2,370 \\
\hline 6,396
\end{tabular}

b. Reduction of computer costs due to ground water site inventory (GWSI) data entry, error correction and calculations via minicomputer

Estimated Time Saved (Months) Grade Level Cost Savings

\begin{tabular}{rlr}
1.00 & GS -11 & $\$ 1,819$ \\
3.50 & GS -9 & 5,264 \\
2.00 & GS-4 & 1,774 \\
\hline & & $\$ 8,857$
\end{tabular}

2. Hydrologic modeling

a. Reduction of computer costs due to hydrologic model coding, debugging and data entry being transferred to minicomputer

Estimated Time Save (Months) Grade Level Cost Savings

$\begin{array}{rlr}4.00 & \text { GS-12 } & \$ 8,720 \\ 1.00 & \text { GS-4 } & 887 \\ & & \$ 9,607\end{array}$


b. Cost savings in model calibration

Estimated Time Saved (Months) Grade Level Cost Savings

$$
2.00 \quad \text { GS }-12 \quad \frac{\$ 4,360}{\$ 4,360}
$$

c. Reduction in costs due to archiving of model test runs on minicomputer

$\begin{array}{ccc}\text { Estimated Time Saved (Months) } & \text { Grade Level } & \frac{\text { Cost Savings }}{2.00} \\ \text { GS-12 } & \frac{\$ 4,360}{\$ 4,360}\end{array}$

d. Cost reduction due to preparation of model output including maps and hydrographs on minicomputer

Estimated Time Saved (Months) Grade Level $\underline{\text { Cost Savings }}$

\begin{tabular}{rlr}
1.00 & GS-12 & $\$ 2,180$ \\
1.00 & GS-9 & 1,504 \\
1.00 & GS-4 & 887 \\
\hline & & $\$ 4,571$
\end{tabular}

TOTAL $\$ 38,151$

C. Reports Section

1. Archiving and reprinting

a. Savings due to reports being online on the minicomputer

Estimated Time Saved (Months) Grade Level Cost Savings

$$
0.50 \quad \text { GS }-4 \quad \frac{\$ 444}{\$ 444}
$$

2. Annual report headers

a. Savings due to headers being kept online for updating and printing

Estimated Time Saved (Months) Grade Level Cost Savings

0.50

GS-6

$\$ 553$

2.00

GS-4

$$
\frac{1,774}{\$ 2,327}
$$


3. Bibliographic searches

a. Reduction in costs due to keeping bibliographic data online

Estimated Time Saved (Months) Grade Level Cost Savings

1.00

GS-9

$\frac{\$ 1,504}{\$ 1,504}$

TOTAL $\$ 4,275$

D. Administrative Section

1. Inventory of controlled property

a. Savings realized by placing inventory online on minicomputer

Estimated Time Saved (Months)

Grade Level Cost Savings

$\begin{array}{rrr}1.50 & \text { GS-6 } & \$ 1,659 \\ 1.00 & \text { GS }-4 & \frac{887}{\$ 2,546}\end{array}$

2. Payroll and fiscal data

a. Savings resulting from placing data online on minicomputer

Estimated Time Saved (Months)

Grade Level Cost Savings

\begin{tabular}{rlr}
0.20 & GS -14 & $\$ \quad 613$ \\
0.20 & GS -13 & 518 \\
1.00 & GS -9 & 1,504 \\
2.00 & GS -4 & 1,774 \\
\hline 4,409
\end{tabular}

3. Travel documents, requisitions and purchase orders

a. Savings resulting from placing information online on minicomputer

Estimated Time Saved (Months)

$\begin{array}{cc}\text { Grade Level } & \text { Cost Savings } \\ \text { GS-5 } & \frac{\$ 496}{\$ 4} 496\end{array}$

TOTAL $\$ 7,451$ 
E. Computer Section

1. File backup procedures and restoration of purged files

a. Savings resulting from improved control over backup procedures

Estimated Time Saved (Months) Grade Leve1 $\quad$ Cost Savings
0.50
GS-12
$\$ 1,090$
0.50
GS-6
$\frac{553}{\$ 1,643}$

2. Training of users in file management and programming

a. Cost savings due to discontinuance of archaic file management and programming system (OMNIANA)

Estimated Time Saved (Months)

Grade Level

Cost Savings

0.50

GS-12

$\$ 1,090$

0.50

GS-6

553

1.00

GS-4

$\frac{887}{\$ 2,530}$

TOTAL $\$ 4,173$

Estimated personnel cost savings per year $\$ 86,007$ 